\title{
A Review of the Return-Illiquidity Relationship
}

Jozef Drienko ${ }^{1}$

Tom Smith ${ }^{2}$

Anna von Reibnitz ${ }^{3 *}$

${ }^{1}$ Research School of Finance, Actuarial Studies and Statistics, College of Business and Economics, Australian National University, Australia; jozef.drienko@anu.edu.au

${ }^{2}$ Department of Applied Finance and Actuarial Studies, Macquarie University, Australia; tom.smith@mq.edu.au

${ }^{3}$ Research School of Finance, Actuarial Studies and Statistics, College of Business and Economics, Australian National University, Australia; anna.vonreibnitz@anu.edu.au

\begin{abstract}
Amihud (2002) shows that expected market illiquidity has a positive impact on ex ante stock returns, while the reverse relation exists between unexpected illiquidity and contemporaneous returns, suggesting the presence of a priced risk factor. We replicate these findings in-sample, but the out-of-sample results largely lose their significance and monotonic properties in the time-series. This points to a decline in the sensitivity of investors to illiquidity risk over the last two decades, a period during which technological innovations and decimalization have markedly reduced transaction costs and increased stock liquidity. Altering the measurement frequency, refining the data filters and considering alternative test specifications leads to similar results. A cross-validation approach confirms a change point in liquidity occurring post publication of the seminal study. We also show that the findings pertaining to the employed illiquidity measure are driven by scaling the numerator of the ratio by the dollar-traded volume.
\end{abstract}

\footnotetext{
*We would like to thank an anonymous associate editor and an anonymous referee for helpful comments and suggestions that have significantly enhanced the scope of this research. We are particularly grateful to Ivo Welch (the editor) for providing us with helpful guidance throughout this study. Useful comments and suggestions were also provided by Michael Martin. Any errors are our own.
}

Replication data available from:

http://dx.doi.org/10.1561/104.00000052_supp

ISSN 2164-5744; DOI 10.1561/104.00000052

(C) 2019 Jozef Drienko, Tom Smith and Anna von Reibnitz 
Keywords: Liquidity and asset pricing, Illiquidity risk premium, Flight to liquidity JEL Codes: G12

\section{Introduction}

Amihud (2002), henceforth A02, examines the time-series effects of expected market illiquidity on ex ante (excess) stock returns. In contrast to well-known microstructure measures, the paper employs a measure of illiquidity using daily equity data to construct a broad estimate over long sample periods. The illiquidity variable that drives the research, ILLIQ, is defined for each security as a ratio of the daily absolute stock return to its dollar-traded volume on that day, averaged over the year. That is, the ratio calculates the daily absolute (percentage) price change per dollar of volume. This ILLIQ variable is averaged across the stocks in the sample each period to obtain market illiquidity, the expectations of which are estimated from an autoregressive model. Using this measure, A02 finds a consistently positive and significant cross-sectional relationship between stock returns and illiquidity. Extending the analysis to time-series tests shows expected market illiquidity to have a positive and significant effect on ex ante stock returns, while unexpected market illiquidity has a negative and significant effect on contemporaneous stock returns. These effects are more pronounced for small stocks, as a flight to liquidity (a substitution from less liquid to more liquid stocks in times of constrained market trading) makes less-traded securities particularly sensitive to changes in illiquidity over time. Overall, the published findings suggest that expected stock returns provide investors with compensation for the lower liquidity of stocks relative to that of Treasuries, contributing an explanation to the high equity premium puzzle.

In revisiting this analysis, we begin by considering the same sample period (1964 to 1996), method and data selection criteria employed by A02 to replicate the reported findings. Then, we repeat the same tests using out-of-sample (1997 to 2015) and full sample (1964 to 2015) periods to examine whether the original results and conclusions endure. Robustness modifications, in the form of extra data filters to refine the sample and alternative test specifications to extend the original methodology, are added and examined. Subsequently, we investigate alternative interpretations of the employed illiquidity ratio and look for change points in the time-series via a cross-validation approach to identify potential trends over the full sample period.

Our findings are as follows. First, we are able to replicate the cross-sectional and time-series results reported by A02. Ex ante equity returns are an increasing function of expected market illiquidity and unexpected market illiquidity results in lower contemporaneous returns. Moreover, tests on the size portfolios corroborate the hypotheses that the illiquidity effect is stronger for less liquid stocks, as expected illiquidity decreases monotonically in size and unexpected illiquidity increases monotonically in size. Our results, while not identical to the published values, are consistent in sign, magnitude, and statistical significance. 
Second, the analogous in-sample findings largely dissipate out-of-sample. While the cross-sectional illiquidity remains positive and significant for all model specifications, it markedly decreases in magnitude. The time-series regression terms maintain the same sign but lose their monotonic properties and much of their significance. This is consistent with the considerable reduction in the magnitude of the market illiquidity measure over the last two decades, with values persistently close to zero post 2003. Hence, the employed illiquidity ratio no longer induces a risk premium in today's equity market and the difference in the reaction between small and large stocks to changes in illiquidity is no longer distinct.

The observed improvement in stock liquidity has been noted in the literature. Chordia et al. (2011) point to technological innovations that have resulted in widespread reductions in trading costs and transformed access to stock trading, spurring demand for equity transactions. Bessembinder (2003) and Chakravarty et al. (2004) point to regulatory changes in the form of exchangewide decimalization of security prices in 2001 as a further reason for the reduction in transaction costs. Ben-Rephael et al. (2015) examine a number of liquidity proxies, including the A02 measure, to determine whether the liquidity premium is still significant in a more recent sample of stocks or whether it has turned into a second-order effect with declining magnitude. The authors conclude that the premium was large and robust until the mid-1980s, since becoming a small second-order effect. That is, the economically significant results pertaining to the liquidity premium reported in prior studies are driven by early period observations, a finding we confirm in our replication.

Third, we consider plain specification robustness tests over the full sample period. We refine the data to exclude assets other than common stocks more directly, adjust for missing stock prices to ensure that returns are daily (as opposed to cumulative), alter the dividend yield to avoid the beginning of period price appearing on both sides of the cross-sectional model, substitute winsorizing for trimming at the same cut-off levels, retain penny stocks, and adjust the illiquidity metric for inflation. The aforementioned results are robust to these refinements.

Fourth, in further tests and discussions, we consider alternative interpretations of the illiquidity measure, examining whether ILLIQ could instead be capturing the effect of stock market volatility (VOL) on expected returns. We find a significant positive relation between VOL and ILLIQ, driven by the strong relation that volatility has with the numerator of the illiquidity measure, namely the absolute value of stock returns. Despite this, however, we ultimately conclude that it is not the numerator of the A02 illiquidity ratio but rather its denominator, dollar-traded volume, that is driving the results reported in the seminal study. That is, employing the inverse of the dollar-traded volume in the same manner as ILLIQ leads to analogous findings in terms of sign, magnitude, and significance as those reported in A02. As dollar volume is a natural measure of liquidity, this result adds weight to the interpretation by $\mathrm{A} 02$ of the existence of a priced illiquidity risk factor, although the premium has declined substantially post-publication. 
To formalize whether the end of the A02 sample period could be deemed a significant change point in the demand for an illiquidity premium by investors, we finally perform a $k$-fold cross-validation study. The in-sample period (33 years, 1964 to 1996) is employed as a training set in which the coefficients are estimated and fitted to a test set comprising the out-of-sample data (19 years, 1997 to 2015), producing a mean absolute error between the fitted and actual value for the independent variable (excess market returns). To generate a benchmark, 1,000 simulations create test sets with the same proportion of observations (19 years, or $36.5 \%$ of the data) randomly sampled (with replacement) from the full period. The remaining observations are allocated to training sets in the same fitting process, resulting in a mean absolute error for each simulation. We find that only $16.9 \%$ of the mean absolute errors from the simulations exceed that from the post-publication sample, providing further evidence of a change in investor attitudes toward illiquidity risk in the past two decades.

\section{Data and Sample Selection}

We begin our analysis of the data by constructing a replicated sample using the time and database specifications employed by A02 in an effort to corroborate the published results. Initially, the effect of illiquidity on returns is restricted to securities traded on the New York Stock Exchange (NYSE) over the sample period January 1963 to December 1997, using the Center for Research in Security Prices (CRSP) daily and monthly stock files. Every stock included in the cross-sectional regressions for month $m$ of year $y$ must satisfy a four-stage filtering process, nominated by A02. The four conditions consist of the stock being listed at the end of year $y-1$ and having more than 200 days of return and volume data during that year, the stock price being greater than $\$ 5$ at the end of year $y-1$, the stock having market capitalization data at the end of year $y-1$ and the stock surviving a $1 \%$ trim of the top and bottom tails of the distribution. In our study, these criteria result in a sample comprising between 1,038 and 2,272 stocks over the initial sample period, compared to a sample size of 1,061 to 2,291 stocks reported in A02.

For each sample stock $i$, the illiquidity variable ILLIQ ${ }_{i y}$ is measured as a ratio of the daily absolute stock return to its dollar-traded volume on that day, averaged over the number of days for which data are available in year $y$. That is, the ratio calculates the daily absolute (percentage) price change per dollar of volume. Thus, holding other things constant, higher trading volume would cause a lower illiquidity measure. Since the shares of small firms are generally more illiquid, we expect $\mathrm{SIZE}_{i y}$, the market value of sample stock $i$ at the end of the year $y$ (sourced from CRSP) to be negatively correlated with ILLIQ ${ }_{i y}$. A02 calculates the correlation between ILLIQ ${ }_{i y}$ and $\ln$ SIZE $_{i y}$ in each year across stocks, subsequently averaging the yearly coefficients over the 34 sample years to arrive at a correlation result of -0.614 . Using an identical approach, we find a correlation coefficient of 
-0.632. This correlation calculation is repeated by A02 for ILLIQ ${ }_{i y}$ and SDRET ${ }_{i y}$, the standard deviation of the daily returns on stock $i$ in year $y$. The published study finds this correlation to be 0.278 , compared to our value of 0.224 .

Panel A of Table 1 reproduces the summary statistics reported in A02 (Table 1, p. 38) for ILLIQ $i y$, SIZE $_{i y}, \operatorname{DIVYLD}_{i y}$, and $\operatorname{SDRET}_{i y} .{ }^{1} \operatorname{DIVYLD}_{i y}$ is the dividend yield, calculated as the sum of the dividends (from CRSP) for stock $i$ in year $y$ divided by the end-of-year price for that stock. Despite using the same period (1963 to 1996), data specification and sample selection criteria detailed in the published study, our replicated statistics, displayed in Panel B, are not identical. However, the summary statistics (Panel B) for all the considered variables are similar to the published findings (Panel A). Overall, the matching values are comparable as well as consistent in sign, magnitude, and range.

Table 1 also reports matching summary statistics for the additional sample periods we consider throughout this study. Panel C provides findings for the out-of-sample period 1997 to 2014. The estimated statistics are markedly different to those from the earlier sub-sample, particularly for ILLIQ ${ }_{i y}$ and SIZE ${ }_{i y}$. The outof-sample stocks are more liquid by an order of magnitude as well as considerably larger with respect to market capitalization. In fact, the maximum annual value of the size variable ( $\$ 2,234.9$ million) over the 1963 to 1996 sample period is less than the corresponding minimum value over the 1997 to 2014 period $(\$ 2,834.1$ million). The substantial increase in liquidity in recent decades is consistent with the market microstructure literature. Chordia et al. (2011), for example, record an increase in the value-weighted average monthly share turnover (on the NYSE) from $5 \%$ at the beginning of 1993 to $26 \%$ at the end of 2008. A 90 fold increase in the average daily number of transactions during the same period is also reported, driven by reductions in trading costs, technological innovations, the availability of online brokerage accounts, and the capacity of exchanges to accommodate large trading volumes.

The statistics pertaining to DIVYLD $_{i y}$ and SDRET $_{i y}$ remain largely stable post 1996. As is to be expected, the descriptive statistics estimated for the full sample period (1963 to 2014), reported in Panel D, reflect a merging of the more illiquid and lower capitalization (1963 to 1996) sample with the less illiquid and higher capitalization (1997 to 2014) sample. The correlation coefficient between ILLIQ ${ }_{i y}$ and $\ln \operatorname{SIZE}_{i y}\left(\operatorname{SDRET}_{i y}\right)$ is $-0.490(0.015)$ over the out-of-sample period and $-0.583(0.152)$ over the full sample period.

\section{Replicated and Out-of-Sample Results}

We start by considering a cross-sectional model that is identical to the one employed in A02 (the results from which are displayed in A02 Table 2, p. 41). The test

\footnotetext{
${ }^{1}$ These stock characteristics are used as lagged regressors in subsequent cross-sectional tests. To illustrate, the 1963 to 1996 characteristics are regressed on 1964 to 1997 stock returns and, in out-of-sample tests, the 1997 to 2014 characteristics are regressed on 1998 to 2015 stock returns.
} 


\begin{tabular}{|c|c|c|c|c|c|c|}
\hline Variable & $\begin{array}{l}\text { Mean of } \\
\text { Annual } \\
\text { Mean }\end{array}$ & $\begin{array}{c}\text { Mean of } \\
\text { Annual } \\
\text { S.D. }\end{array}$ & $\begin{array}{c}\text { Median } \\
\text { of Annual } \\
\text { Means }\end{array}$ & $\begin{array}{c}\text { Mean of } \\
\text { Annual } \\
\text { Skewness }\end{array}$ & $\begin{array}{l}\text { Min. } \\
\text { Annual } \\
\text { Mean }\end{array}$ & $\begin{array}{c}\text { Max. } \\
\text { Annual } \\
\text { Mean }\end{array}$ \\
\hline \multicolumn{7}{|c|}{ Panel A: The Published Summary Statistics (1963 to 1996)_-Table 1 in Amihud (2002) } \\
\hline ILLIQ & 0.337 & 0.512 & 0.308 & 3.095 & 0.056 & 0.967 \\
\hline SIZE(\$million) & 792.6 & $1,611.5$ & 538.3 & 5.417 & 263.1 & $2,195.2$ \\
\hline DIVYLD (\%) & 4.14 & 5.48 & 4.16 & 5.385 & 2.43 & 6.68 \\
\hline SDRET & 2.08 & 0.75 & 2.07 & 1.026 & 1.58 & 2.83 \\
\hline \multicolumn{7}{|c|}{ Panel B: The Replicated Summary Statistics (1963 to 1996) } \\
\hline ILLIQ & 0.278 & 0.405 & 0.263 & 3.020 & 0.053 & 0.889 \\
\hline SIZE (\$million) & 888.0 & $1,752.5$ & 570.91 .1 & 5.249 & 276.5 & $2,234.9$ \\
\hline DIVYLD (\%) & 4.03 & 5.52 & 3.86 & 5.119 & 2.55 & 6.84 \\
\hline SDRET & 2.01 & 0.72 & 1.99 & 1.066 & 1.52 & 2.76 \\
\hline \multicolumn{7}{|c|}{ Panel C: The Out-of-Sample Summary Statistics (1997 to 2014) } \\
\hline ILLIQ & 0.030 & 0.073 & 0.022 & 5.107 & 0.006 & 0.065 \\
\hline SIZE (\$million) & $4,378.4$ & $10,143.1$ & $4,198.3$ & 5.323 & $2,834.1$ & $6,930.1$ \\
\hline DIVYLD (\%) & 3.34 & 4.68 & 3.22 & 7.063 & 2.63 & 5.89 \\
\hline SDRET & 2.16 & 1.00 & 1.95 & 1.292 & 1.56 & 3.97 \\
\hline \multicolumn{7}{|c|}{ Panel D: The Full Sample Summary Statistics (1963 to 2014) } \\
\hline ILLIQ & 0.192 & 0.290 & 0.100 & 3.742 & 0.006 & 0.889 \\
\hline SIZE (\$million) & $2,096.3$ & $4,656.9$ & $1,494.0$ & 5.274 & 276.5 & $6,930.1$ \\
\hline DIVYLD (\%) & 3.79 & 5.23 & 3.46 & 5.792 & 2.55 & 6.84 \\
\hline SDRET & 2.06 & 0.82 & 1.99 & 1.144 & 1.52 & 3.97 \\
\hline
\end{tabular}

Table 1: Summary Statistics for Stock Variables.

Description: This table reports the summary statistics for selected cross-sectional variables, estimated using CRSP data. Panel A reports the statistics published in Amihud (2002). Panel B reports the corresponding statistics of our replication using the same period (1963 to 1996), data specification and sample selection criteria as detailed in the published study. Panel C reports the same information for the out-of-sample period (1997 to 2014). Panel D also reports the same information but for the full sample period (1963 to 2014). Illiquidity, ILLIQ $i y$, is calculated for each stock $i$ as the ratio of its daily absolute stock return to its dollar-traded volume on that day, averaged over year $y$. SIZE $\mathrm{E}_{i y}$ is the end-of-year market capitalization for stock $i$. DIVYLD $i y$ is the dividend yield, calculated as the total annual cash dividend for stock $i$ in year $y$ divided by the end-of-year price. SDRET $i y$ is the standard deviation of the daily return on stock $i$ in year $y$. Included in each year $y$ are NYSE stocks with more than 200 days of data and with an end-of-year price above $\$ 5$. Stocks with the highest and lowest

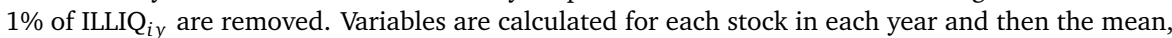
standard deviation, and skewness are estimated across all stocks in each year. Reported below are the mean of the annual mean, standard deviations, and skewness, the medians of the annual mean, and the maximum and minimum annual mean.

Interpretation: The summary statistics of the replication (Panel B), while not identical to the matching values published in Amihud (2002) and replicated in Panel A below, are consistent in sign, magnitude, and range. The statistics for the out-of-sample replication (Panel C) differ from in-sample values, particularly for ILLIQ ${ }_{i y}$ and SIZE $i y$. This more recent sample contains stocks that are more liquid with considerably larger market capitalizations. 
procedure begins by regressing stock returns for each month in year $y$, over the period January 1964 to December 1997 (34 years, generating 408 monthly observations), on stock characteristics that are derived using data from $y-1 .^{2}$ The 408 monthly estimates of each regression coefficient are averaged and tested for statistical significance at the standard cut-off levels. The variable of interest, ILLIQ $_{i y}$, is mean-adjusted before being included in the cross-sectional tests by ILLIQMA $_{i y}=$ ILLIQ $_{i y} /$ AILLIQ $_{y}$. A02 refers to AILLIQ ${ }_{y}$ as market illiquidity, calculated as the average of ILLIQ ${ }_{i y}$ across all the stocks included in the sample in year $y$. The other stock characteristics included in the model are: BETA $i y$, the Scholes and Williams (1977) coefficient from an annual time-series regression of daily equally weighted returns for the size (decile) portfolio to which stock $i$ belongs at the end of year $y$ on equally weighted market portfolio returns; R100 $i y$, the return on stock $i$ over the last 100 days of year $y$; R100YR iy $_{i y}$, the return on stock $i$ from the start of year $y$ to 100 days before its end; and, $\operatorname{SIZE}_{i y}, \operatorname{SDRET}_{i y}$, and DIVYLD ${ }_{i y}$, calculated using the aforementioned definitions.

Table 2 reports the ordinary least squares (OLS) results of the cross-sectional tests. Overall, our findings are consistent with A02 in showing that the employed measure of illiquidity is associated with higher returns. The replicated results (Panel B), estimated using the same sample period, method and data selection criteria, are largely consistent in sign, magnitude, and statistical significance to the published figures (Panel A). The variable of interest, ILLIQMA coefficients that have a mean of 0.145 (0.162 in the published results), a T-statistic of 5.74 (6.55) and a median of 0.120 (0.135). Of the 408 coefficients, $61.3 \%$ (63.4\% in the published results) are positive with a near-zero serial correlation of $-0.01(0.08)$. These effects are robust to the exclusion of all January observations, as well as the division of the original sample period (1964 to 1997) into two subperiods of 204 months each, with ILLIQMA ${ }_{i y}$ remaining positive and statistically significant in all specifications. With respect to the additional coefficients, past returns, measured by $\mathrm{R} 100_{i y}$ and $\mathrm{R} 100 \mathrm{YR}_{i y}$, are consistently positive and significant. However, the other control variables that are reported as significant in A02, while comparable in sign, exhibit only episodic periods of significance in our replicated sample.

The cross-sectional tests are repeated for the out-of-sample (1998 to 2015) and the full sample (1964 to 2015) periods, with the corresponding results reported in Panel C. The illiquidity measure remains positive and significant for all specifications, showing that illiquidity continues to command higher returns subsequent to the seminal study. The mean of the ILLIQMA ${ }_{i y}$ coefficients over the out-of-sample (full sample) period is 0.039 (0.108) with a T-statistic of 3.11 (6.30). The median of the coefficients is 0.037 (0.073). Of the 216 (624) monthly coefficients estimated using out-of-sample (full sample) data, 59.7\% (60.7\%) are positive with a

\footnotetext{
${ }^{2}$ As detailed in A02 and in line with Shumway (1997), we adjust stock returns for delisting using the CRSP Stock Events - Delisting Information file to avoid survivorship bias.
} 


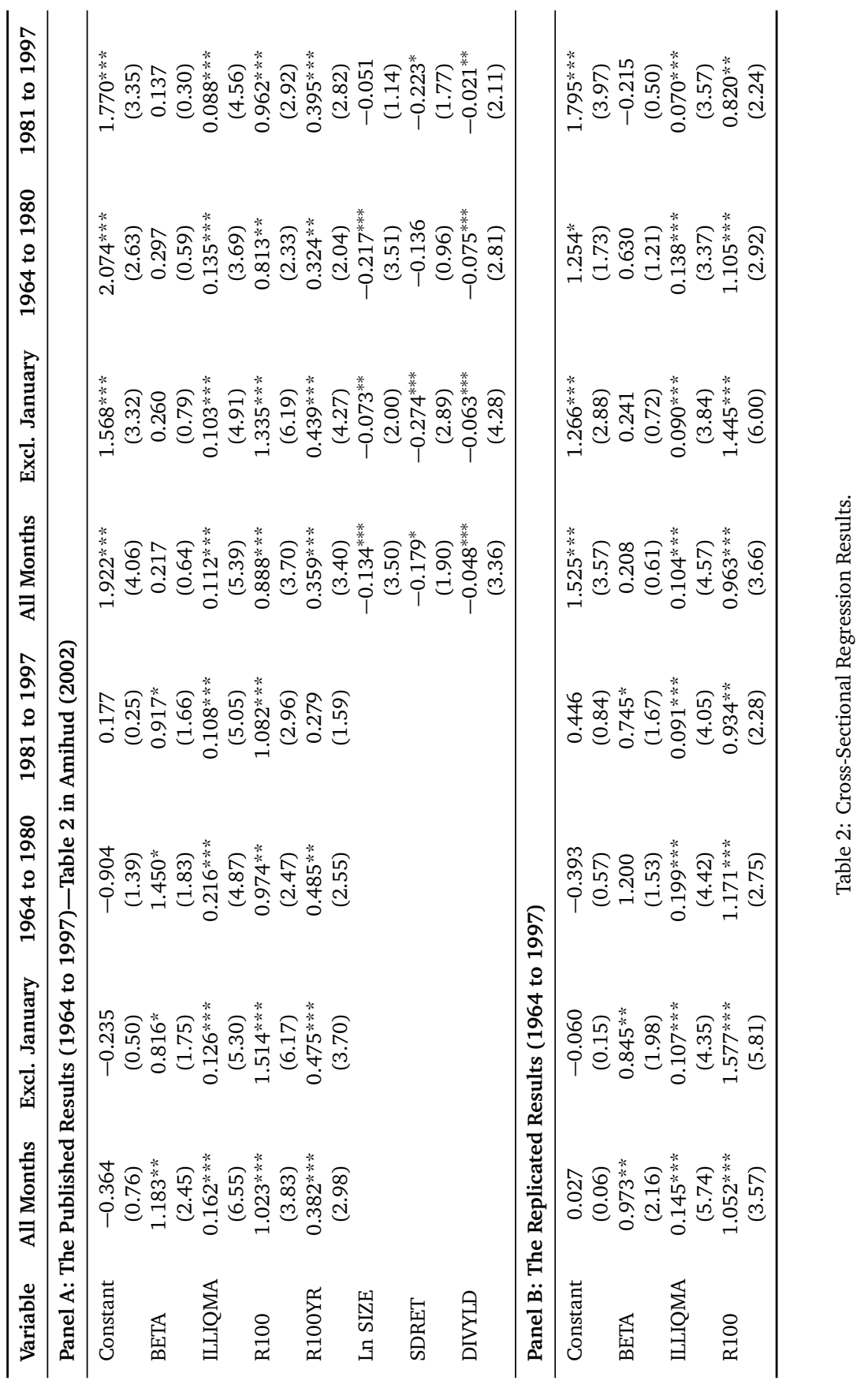




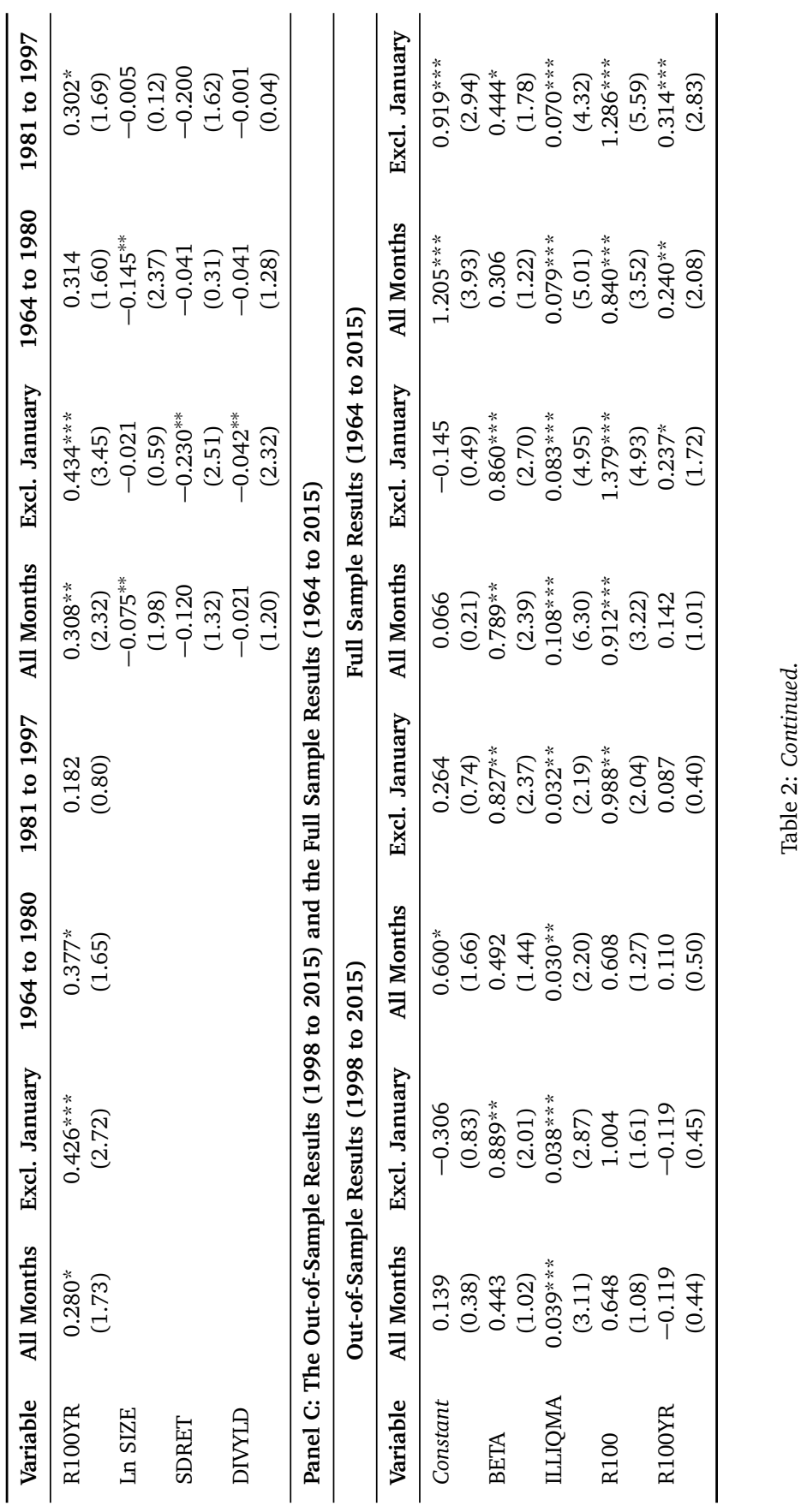




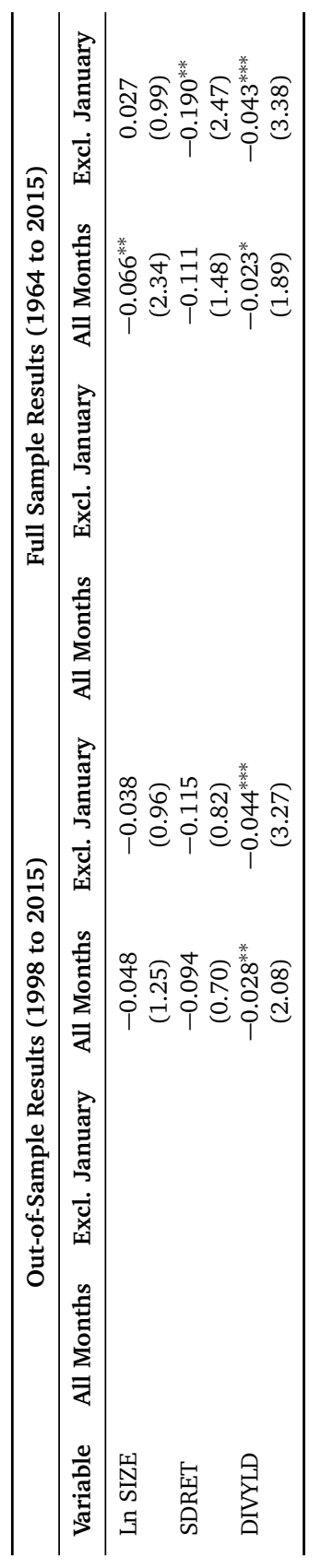

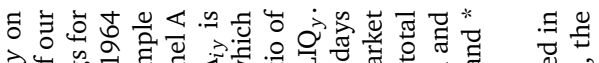
خै

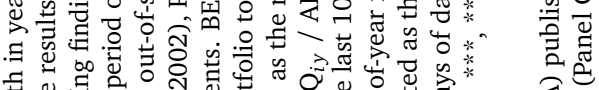

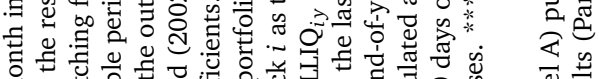

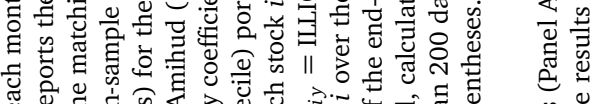

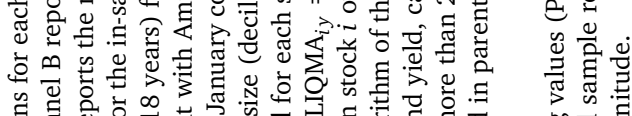

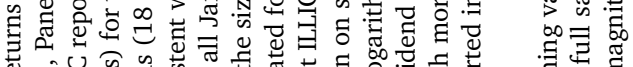

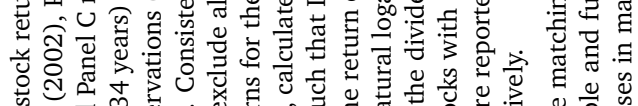

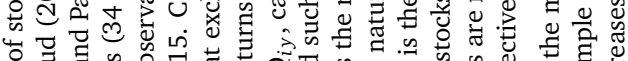

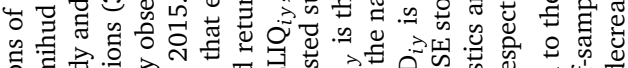

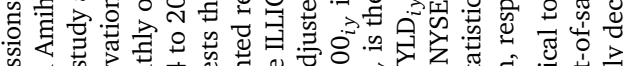

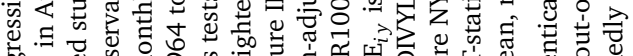
চ艹

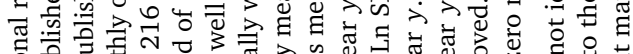

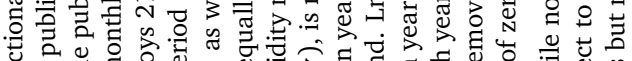

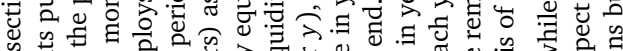

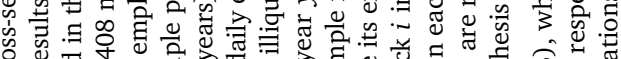

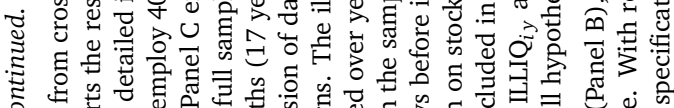

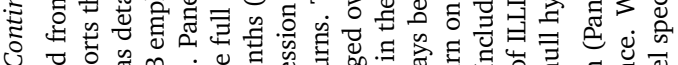

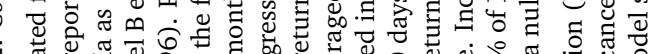

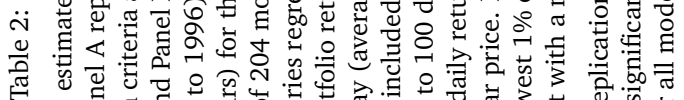

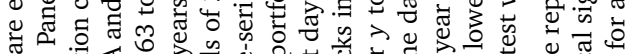

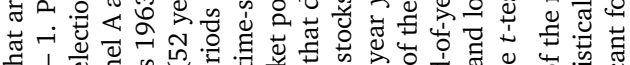

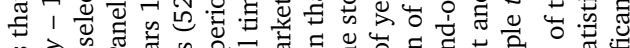

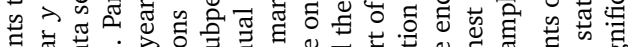

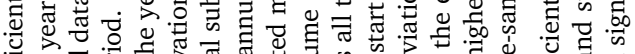

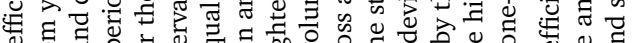

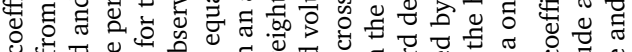

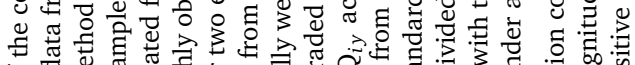

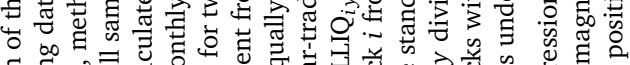

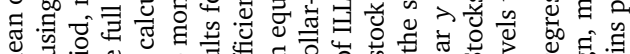

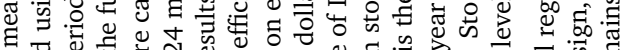
च ळ

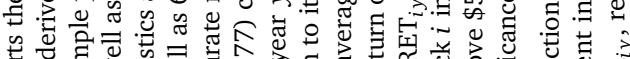

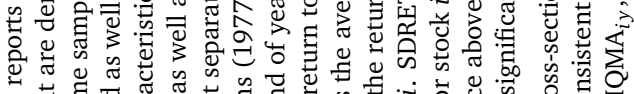

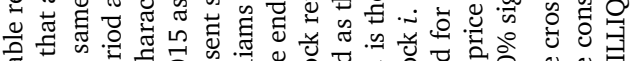

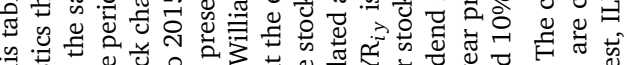
寻.

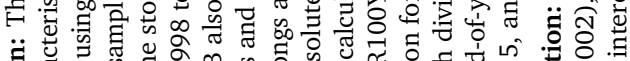

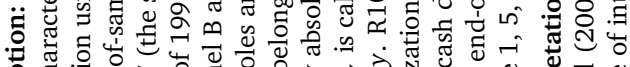

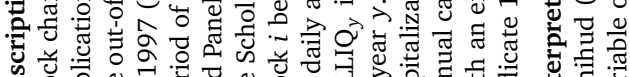

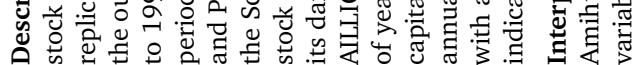


near-zero serial correlation of $-0.04(-0.001)$. What is of considerable difference to the published findings is the magnitude of the illiquidity coefficients over the out-of-sample period. The size of the mean estimates decreases by approximately $70 \%$ in relative terms, a result that is reflective of a substantial increase in stock liquidity post publication. Consistent with A02, $\mathrm{BETA}_{i y}$ and $\mathrm{R} 100_{i y}$ are positive and significant, while DIVYLD ${ }_{i y}$ has negative and significant coefficients, a result that A02 attributes to less risky companies choosing to pay higher dividend yields.

The positive relationship between stock returns and illiquidity found in the cross-section of returns leads A02 to test the impact of market illiquidity over time. A consistent result from a time-series perspective would see investors reacting to higher illiquidity expectations by pricing equity lower, thus demanding higher returns ex ante as compensation for the lower liquidity of stocks relative to Treasuries, which are comparatively more liquid and can be traded in large volumes without price impact or sizable transaction costs. As such, A02 considers whether expected excess stock returns (in excess of the yield on short-term Treasury securities) are an increasing function of expected market illiquidity. Such a finding would indicate that the equity risk premium, found to be too high and labeled as a puzzle by the extant literature (see, for example, Mehra, 2008), contains a premium for illiquidity, contributing an explanation to the debate.

The market illiquidity measure used to drive the time-series analysis is AILLIQ $_{y}$, the annual expectations of which are assumed to follow a first-order autoregressive (AR(1)) process. That is, investors extract their forecasts of illiquidity for year $y\left(\right.$ AILLIQ $\left._{E(y)}\right)$ from information available in year $y-1$ and set market prices accordingly. Higher levels of illiquidity in year $y-1$ increase expected illiquidity in year $y\left(c_{1}>0\right.$ in the equation below). Following A02, we employ a natural logarithmic transformation of the measure. Therefore,

$$
\ln \operatorname{AILLIQ}_{E(y)}=\ln \operatorname{AILLIQ}_{y}=c_{0}+c_{1} \ln \operatorname{AILLIQ}_{y-1}+v_{y},
$$

with investors setting market prices to obtain the desired expected excess returns over year $y$. Formally,

$$
(\mathrm{RM}-\mathrm{Rf})_{y}=f_{0}+f_{1} \ln \operatorname{AILLIQ}_{E(y)}+u_{y}=g_{0}+g_{1} \ln \operatorname{AILLIQ}_{y-1}+u_{y},
$$

where $\mathrm{RM}_{y}$ is the annual market return on the equally weighted market portfolio for NYSE stocks over the year $y$; $\mathrm{Rf}_{y}$ is the yield on a 1-year Treasury bill issued at the start of year $y$; ln $\operatorname{AILLIQ}_{E(y)}$ is the natural logarithm of the expected market illiquidity in year $y$, estimated by an $\operatorname{AR}(1)$ process and using information available at the end of year $y-1 ; v_{y}$ and $u_{y}$ are residual terms; and, ln AILLIQ is the natural logarithm of the market illiquidity measure in year $y$, calculated as the average of ILLIQ ${ }_{i y}$ across all the stocks included in the sample in year $y .^{3}$

\footnotetext{
${ }^{3}$ The data pertaining to the equally weighted market portfolio are sourced from CRSP and the yields on Treasury bills are obtained from the Federal Reserve (Fed) Economic Research database (https://fred.stlouisfed.org/).
} 
Note that $g_{0}=f_{0}+f_{1} c_{0}$ and $g_{1}=f_{1} c_{1}$. An OLS regression of model (1) for the replicated (1b), out-of-sample (1c) and full-sample (1d) periods provides the following findings in comparison to the published results (1a):

$$
\begin{aligned}
& \ln \text { AILLIQ }_{y}=-0.200+0.768 \ln \text { AILLIQ }_{y-1}+v_{y} \\
& (t=) \quad(1.70)(5.89) \quad R^{2}=0.53 \text {, Durbin }- \text { Watson statistic }=1.57 \text {, } \\
& \ln \text { AILLIQ }_{y}=-0.266+0.729 \ln \text { AILLIQ }_{y-1}+v_{y} \\
& (t=) \quad(1.92)(5.57) \quad R^{2}=0.48 \text {, Durbin }- \text { Watson statistic }=1.51 \text {, } \\
& \ln \text { AILLIQ }_{y}=-0.515+0.854 \ln \text { AILLIQ }_{y-1}+v_{y} \\
& (t=) \quad(1.36)(6.83) \quad R^{2}=0.72 \text {, Watson statistic }=1.58 \text {, } \\
& \ln \text { AILLIQ }_{y}=-0.176+0.930 \ln \text { AILLIQ }_{y-1}+v_{y} \\
& (t=) \quad(1.50)(15.95) \quad R^{2}=0.83 \text {, Durbin }- \text { Watson statistic }=1.64 \text {. }
\end{aligned}
$$

For all sample periods, our results are consistent with A02, showing that $c_{1}>0$.

The time-series analysis also extends to unexpected market illiquidity. As noted above, an increase in $\operatorname{AILIQ}_{y-1}$ will drive $\operatorname{AILLIQ}_{E(y)}$ higher, causing expected returns in year $y$ to increase as investors price stocks lower. Hence, an unexpected increase in illiquidity will cause contemporaneous stock returns to decrease due to a fall in stock prices in response. To examine this, A02 modifies (2) to include an unexpected illiquidity component:

$$
(\mathrm{RM}-\mathrm{Rf})_{y}=g_{0}+g_{1} \ln \operatorname{AILLIQ}_{y-1}+g_{2} \ln \operatorname{AILLIQ}_{U(y)}+u_{y},
$$

where ln AILLIQ $_{U(y)}$ is the natural logarithm of the unexpected market illiquidity in year $y$, equal to the residual term $\left(v_{y}\right)$ from the AR(1) process in (1). Prior to being included in the model, the $v_{y}$ coefficients are adjusted for the bias-correction method of Kendall (1954), which is used to mitigate the upward bias present in $g_{1} \cdot{ }^{4}$ The tested hypotheses take the form $g_{1}>0$ (higher expected market illiquidity results in higher ex ante returns) and $g_{2}<0$ (higher unexpected market illiquidity results in lower contemporaneous returns).

To further the research, A02 extends (3) to also consider firm size (a proxy for liquidity), postulating that large and small firms react differently to variations in market illiquidity. Specifically, while increases in expected market illiquidity are likely to cause ex ante returns to rise for all stocks, a flight to liquidity (a substitution from less liquid to more liquid stocks in times of constrained market trading)

\footnotetext{
${ }^{4}$ Specifically, we apply Kendall's (1954) bias-correction method to the estimated coefficients from model (1), displayed in (1a to $1 \mathrm{~d}$ ), as follows. First, we adjust the estimated $c_{1}$ coefficient $\widehat{c_{1}}$ such that $\widehat{c_{1}(\mathrm{adj})}=\widehat{c_{1}}+\left(1+3 \widehat{c_{1}}\right) / T$, where $T$ is the number of regression observations. The intercept $\widehat{c_{0}}$ is adjusted as $\widehat{c_{0}(\mathrm{adj})}=\overline{\ln \text { AILLIQ }_{y}}-\widehat{c_{1}(\operatorname{adj})} \overline{\ln \text { AILLIQ }_{y-1}}$. Finally, the adjusted $v_{y}$ coefficients, equal to $\ln \operatorname{AILLIQ}_{U(y)}$ in model (3), are calculated as $\ln \operatorname{AILLIQ}_{U(y)}=v_{y}(\operatorname{adj})=\ln \operatorname{AILIQ}_{y}-\widehat{c_{0}(\operatorname{adj})}-$ $\widehat{c_{1}(\operatorname{adj})} \ln$ AILLIQ $_{y-1}$.
} 
makes less-traded securities even more sensitive to changes in illiquidity over time, resulting in a higher illiquidity risk premium. To gauge whether stocks that are more thinly traded experience stronger effects from changes in market illiquidity, model (3) is therefore also estimated using returns on size (decile) portfolios. That is, $\mathrm{RM}_{y}$ in (3) is replaced with $\mathrm{RSZ}_{i y}$, the annual returns on a CRSP size-portfolio $i$ in year $y$, where $i=2,4,6,8$, and 10 (portfolio 10 consists of stocks with the largest capitalizations). If the model coefficients $g_{1}$ and $g_{2}$ are denoted as $g_{1}^{i}$ and $g_{2}^{i}$ for each size portfolio $i$, the proposition that the impact of illiquidity is more pronounced for smaller stocks can be examined by studying whether $g_{1}^{2}>g_{1}^{4}>g_{1}^{6}>g_{1}^{8}>g_{1}^{10}>0$ and $g_{2}^{2}<g_{2}^{4}<g_{2}^{6}<g_{2}^{8}<g_{2}^{10}<0$. The results of these tests for all sample periods, as well as the published findings, are shown in Table 3.

We find that the replicated coefficients (Panel B) resemble the published findings (Panel A) in terms of sign, size, and significance. Ex ante equity returns are an increasing function of expected market illiquidity, as evidenced by a positive and significant $g_{1}$ term, while a negative and significant $g_{2}$ coefficient indicates that unexpected market illiquidity results in lower contemporaneous equity returns. Moreover, tests on the size portfolios corroborate the hypotheses that the illiquidity effect is stronger for less liquid stocks as $g_{1}^{i}$ (expected illiquidity) decreases monotonically in size and $g_{2}^{i}$ (unexpected illiquidity) increases monotonically in size. Overall, these findings suggest that expected stock returns provide investors with compensation for the lower liquidity of stocks relative to Treasuries, contributing an explanation to the high equity premium puzzle.

The results pertaining to the out-of-sample (Panel C) and full sample (Panel D) periods are not as convincing. While the positive $g_{1}$ term remains, as does the decline in $g_{1}^{i}$ as firm size increases (no longer monotonic in Panel C), the magnitudes of the expected liquidity coefficients are no longer large enough to render the factor statistically significant. The results are still significant and consistent with the published findings for both sample periods with respect to $g_{2}$, but the monotonic increase in $g_{2}^{i}$ is lost in the out-of-sample tests. These findings indicate a decline in the sensitivity of investors to the illiquidity risk present in the market, a likely reflection of the significant expansion of equity trading post publication as outlined by the extant literature (Chordia et al., 2001) and confirmed in our summary statistics. A time-series plot of $\mathrm{AILIQ}_{y}$, presented in the appendix (Figure A1), shows a considerable reduction in the magnitude of the market illiquidity measure over the last two decades, with its values persistently close to zero post $2003 .^{5}$

\footnotetext{
${ }^{5}$ This declining trend of illiquidity for the past two decades is not simply a reflection of the rapid growth in market capitalization over the same timeframe. To confirm this, we calculate the Brennan et al. (2013) modified ILLIQ measure, and examine its time-series over the period 1963 to 2015. This modified illiquidity measure replaces dollar volume, the denominator of the A02 ILLIQ metric, with turnover, thereby removing the effect of firm size from the illiquidity calculation. The Brennan et al. (2013) illiquidity metric also displays a downward trend through time, particularly since the late 1990s.
} 


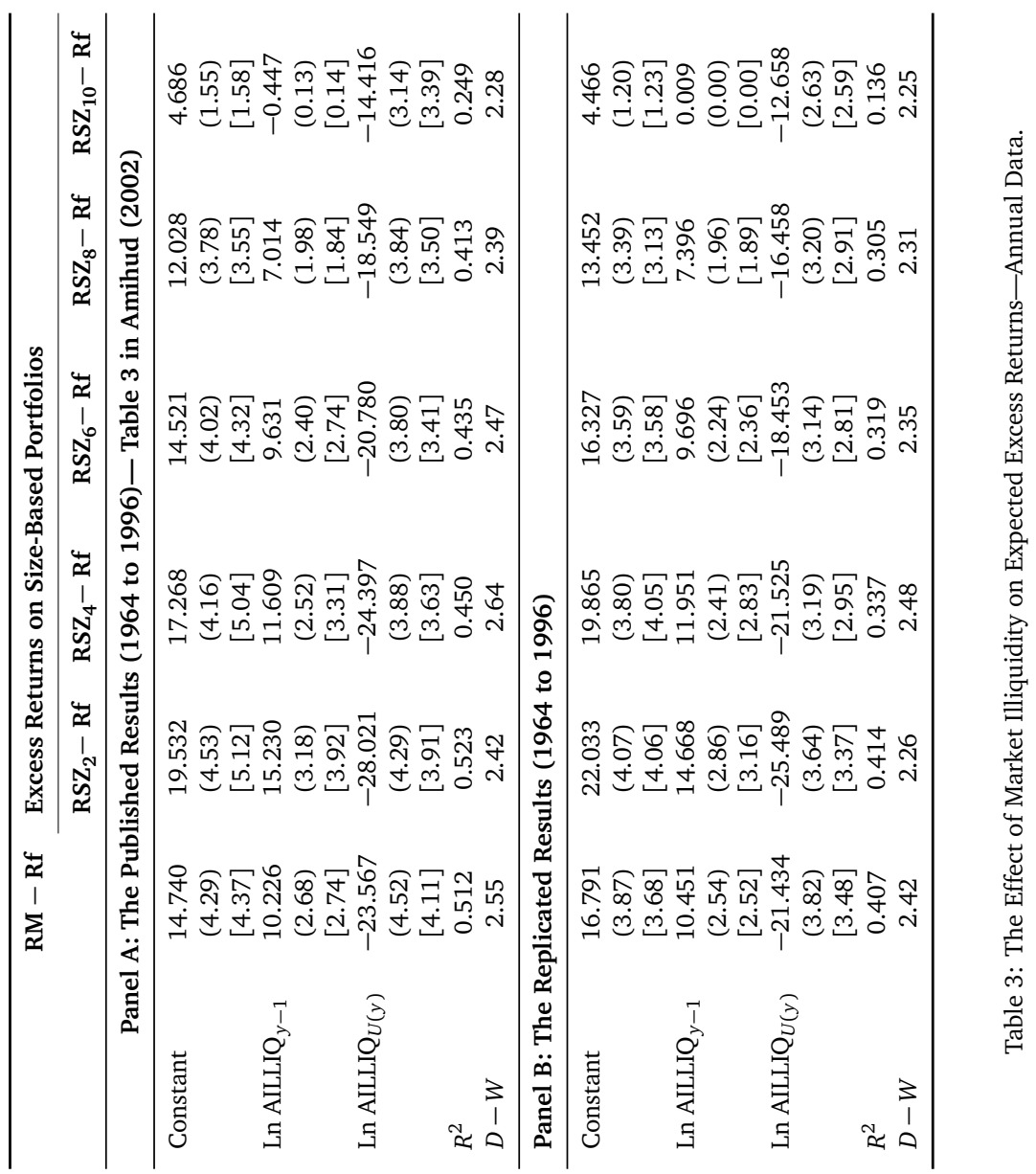




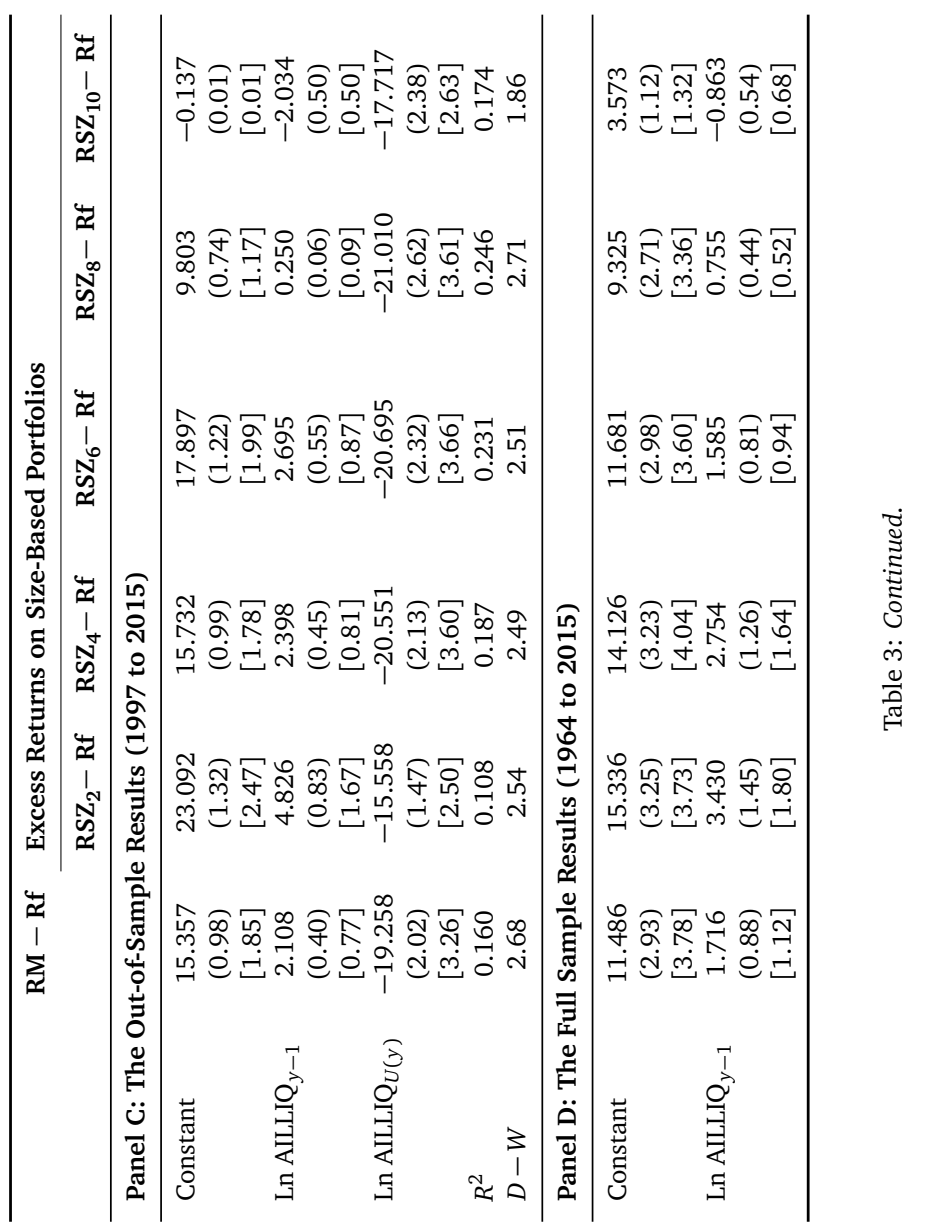




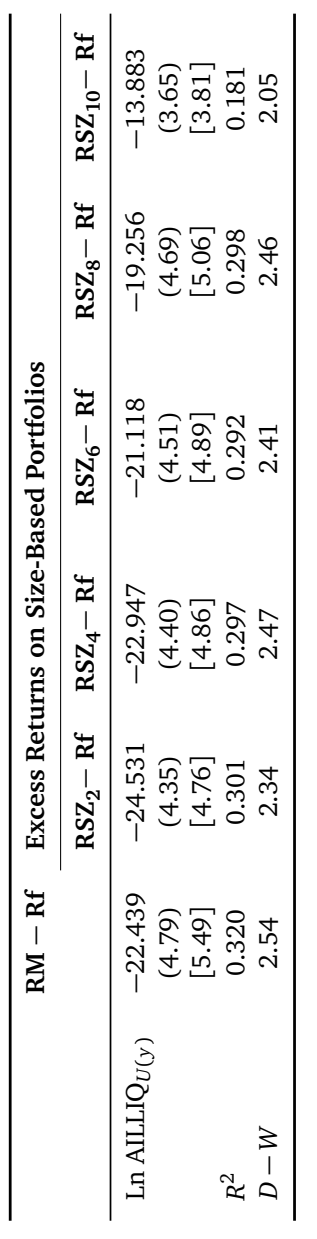

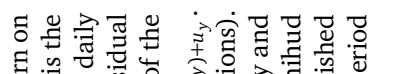

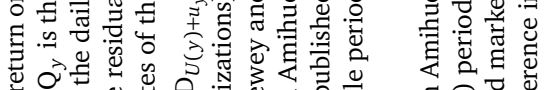

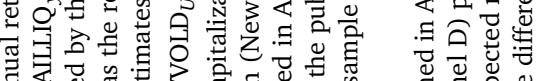

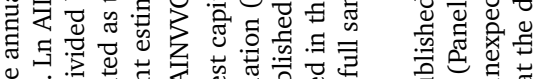

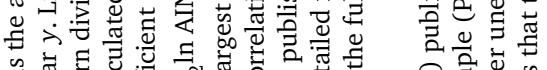

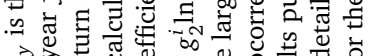

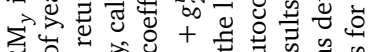

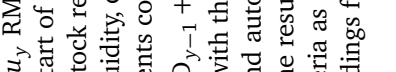

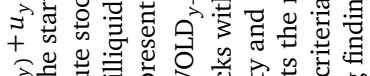

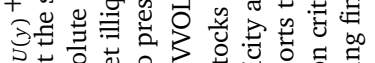

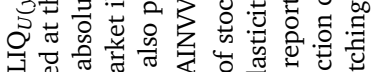

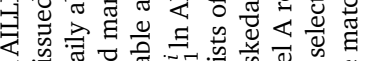

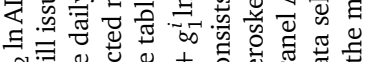
o

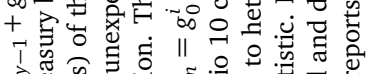

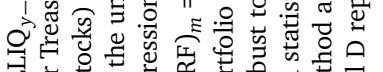

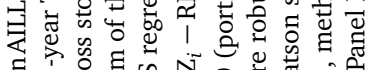

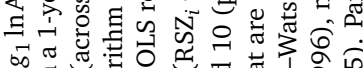

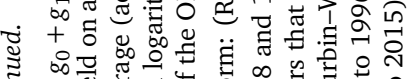

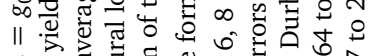

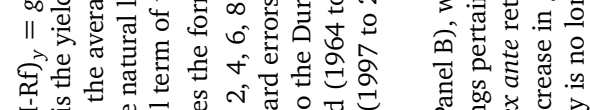

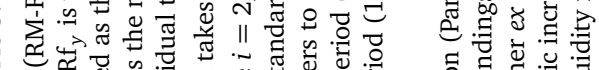
बै

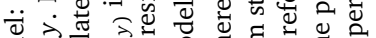

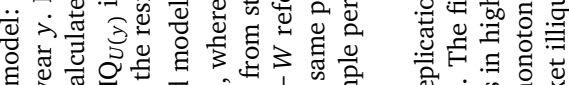

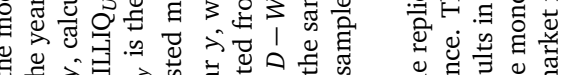

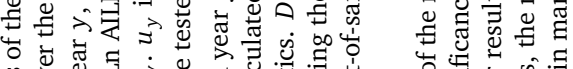

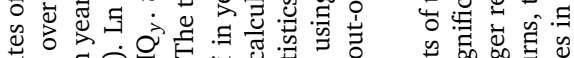
w

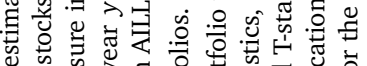

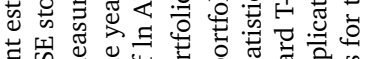

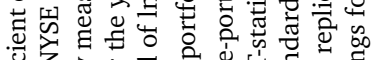

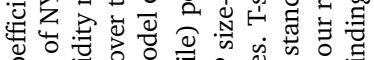

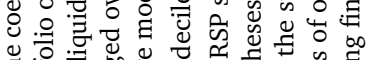
을 연.

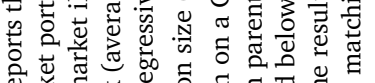

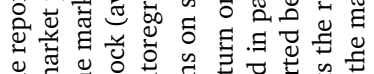

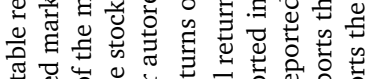

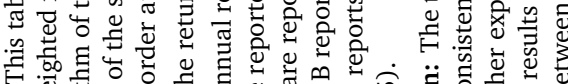
㻤

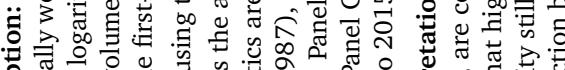

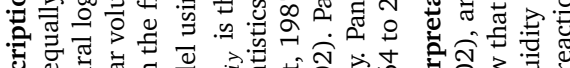

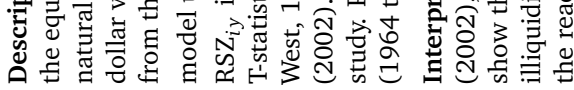


The continued significance of the negative relationship between unexpected illiquidity and contemporaneous returns against the disappearing significance of the previously positive association between expected illiquidity and future returns is not entirely surprising. As the stock market in recent decades is substantially more liquid than it once was, the expectation of a decline in liquidity now carries less cause for concern. Portfolios can be adjusted with greater ease, and a change in expectations is unlikely to be associated with other events that would catch investors off-guard. A sharp decrease in unexpected illiquidity, on the other hand, remains a significant challenge as it signifies a change for which market participants are unprepared regardless of the level of underlying liquidity among stocks. This leaves investors with little time to plan any necessary portfolio adjustments, increasing the cost of these changes and, therefore, attracting a premium with respect to unexpected illiquidity. In addition, the significance of the unexpected illiquidity factor is substantially larger relative to the expected illiquidity factor in-sample, highlighting the greater sensitivity to the former in comparison to the latter. Hence, a general increase in liquidity over the last two decades is likely to render the expected illiquidity premium insignificant prior to unexpected illiquidity in the data.

The absence of a monotonic relation in the out-of-sample coefficients shows that the difference in the reaction between small and large firms to changes in market illiquidity is no longer distinct in a share market that is more liquid. Therefore, the flight to liquidity effect, still observed for the full sample, is a product of a period prior to technological innovations that have transformed access to stock trading (via, for example, automated algorithmic trading, online brokerage accounts and inter-market linkages) and resulted in substantial reductions in trading costs (in terms of commission or brokerage, bid-ask spread and price impact), spurring demand for equity transactions. ${ }^{6,7}$ The exchange-wide decimalization of security prices in 2001 is also a contributing factor in reducing transaction costs out-ofsample, as the regulatory change resulted in tighter spreads due to the use of smaller increments compared to fractions (see, for example, Bessembinder, 2003 or Chakravarty et al., 2004).

Our results corroborate the findings of Ben-Rephael et al. (2015) who examine a number of liquidity proxies, including the $\mathrm{A} 02$ measure, to determine whether the liquidity premium is still significant in a more recent sample of stocks or whether it has turned into a second-order effect with declining magnitude. The authors conclude that the premium was large and robust until the mid-1980s, since becoming a

\footnotetext{
${ }^{6}$ Refer to, for example, Chakravarty et al. (2005) and French (2008), or Chordia et al. (2001, 2011).

${ }^{7}$ In 1998, the second year in our out-of-sample replication, the Securities and Exchange Commission enacted Regulation ATS (Alternative Trading System, available at http://www.sec.gov/rules/final/3440760.txt), inducing the widespread use of both electronic communication networks (consolidated public quote streams) and dark pools to match buy and sell orders more efficiently. The competitive pressures from ATSs have forced legacy exchanges like the NYSE to innovate, allowing investors to transact shares faster, cheaper and easier in larger volumes.
} 
small second-order effect. That is, the economically significant results pertaining to the liquidity premium reported in prior studies are driven by early period observations, a finding we confirm in this replication. The authors are able to identify statistically significant results only among small stocks listed on NASDAQ, whose market capitalization accounts for approximately $0.5 \%$ of the total market capitalization of all publicly listed equity. The liquidity effect is absent among all other common stocks.

To complete our replication of A02, we repeat the time-series analysis with monthly measures of illiquidity and add control variables to account for the impact of the January effect, the default yield premium (the yield spread between longterm BAA-rated and AAA-rated corporate bonds) and the term yield premium (the yield spread between long-term Treasury bonds ${ }^{8}$ and 3-month Treasury bills) on ex ante (excess) stock returns. The monthly illiquidity measure, MILLIQ ${ }_{m}$, is again calculated as the average (across stocks) of the daily absolute stock return divided by the daily dollar volume of the stock, but averaged over the trading days in month $m$ (instead of year $y$ ). The AR(1) model detailed in (1) is re-estimated to yield the following coefficients for the replicated (4b), out-of-sample (4c) and full-sample (4d) periods in comparison to the published results (4a):

$$
\begin{aligned}
& \ln \text { MILLIQ }_{m}=0.313+0.945 \ln \text { MILLIQ }_{m-1}+v_{m} \\
& (t=) \quad(3.31)(58.36) \quad R^{2}=0.89 \text {, Durbin }- \text { Watson statics }=2.34 \text {, } \\
& \ln \text { MILLIQ }_{m}=-0.052+0.951 \ln \text { MILLIQ }_{m-1}+v_{m} \\
& (t=) \quad(2.71)(60.16) \quad R^{2}=0.90 \text {, Durbin }- \text { Watson statistics }=2.06 \text {, } \\
& \ln \text { MILLIQ }_{m}=-0.068+0.980 \ln \text { MILLIQ }_{m-1}+v_{m} \\
& (t=) \quad(1.59)(75.74) \quad R^{2}=0.96 \text {, Durbin }- \text { Watson statistics }=1.70 \text {, } \\
& \ln \text { MILLIQ }_{m}=-0.029+0.987 \ln \text { MILLIQ }_{m-1}+v_{m} \\
& (t=) \quad(1.97)(150.59) \quad R^{2}=0.97 \text {, Durbin }- \text { Watson statistics }=2.00 \text {. }
\end{aligned}
$$

The regression output clearly indicates first-order autocorrelation of the monthly illiquidity measure for all sample periods with $c_{1}$ and $R^{2}$ being close to one, consistent with A02.

After being adjusted for the bias-correction method of Kendall (1954), the residuals $\left(v_{m}\right)$ from model ( $4 \mathrm{~b}$ to $4 \mathrm{~d}$ ) are used to measure the monthly unexpected illiquidity, MILLIQ ${ }_{U(m)}$, in month $m$. Hence, the monthly version of model (3)

\footnotetext{
${ }^{8}$ A02 does not specify the maturity of the long-term bond. However, the bond yield data available from the Fed have enough data, to satisfy the A02 sample period, only for the 10-year Treasury bond. Therefore, the long-term bond yield applied in our replication pertains to the 10-year Treasury bond.
} 
takes the form:

$$
(\mathrm{RM}-\mathrm{Rf})_{m}=g_{0}+g_{1} \ln \mathrm{MILLIQ}_{m-1}+g_{2} \ln \mathrm{MILLIQ}_{U(m)}+g_{3} \mathrm{JANDUM}_{m}+u_{m},
$$

where $\mathrm{RM}_{m}$ is the monthly market return on the equally weighted market portfolio for NYSE stocks over the month $m$; $\mathrm{Rf}_{m}$ is the yield on a 1-month Treasury bill issued at the start of month $m$; $\ln$ MILLIQ $_{m}$ is the natural logarithm of the market illiquidity measure in month $m$, calculated as the average of ILLIQ im $_{\text {across all }}$ the stocks included in the sample in month $m$; $\ln$ MILLIQ $_{U(m)}$ is the natural logarithm of the unexpected market illiquidity in month $m$; $\mathrm{JANDUM}_{m}$ is a dummy variable equal to one in the month of January and zero otherwise; and, $u_{m}$ is the residual term. Expanding model (5) to control for the effects of the two bond yield premiums results in:

$$
\begin{array}{r}
(\mathrm{RM}-\mathrm{Rf})_{m}=g_{0}+g_{1} \ln \mathrm{MILLIQ}_{m-1}+g_{2} \ln \mathrm{MILLIQ}_{U(m)}+g_{3} \mathrm{JANDUM}_{m}+ \\
g_{4} \mathrm{DEF}_{m-1}+g_{5} \mathrm{TERM}_{m-1}+u_{m},
\end{array}
$$

where $\mathrm{DEF}_{m}$ is the default yield premium in month $m ;{ }^{9}$ and, $\mathrm{TERM}_{m}$ is the term yield premium in month $m .^{10}$ As before, to gauge the effects of illiquidity on firms of varying size, models (5) and (6) are also estimated using returns on size (decile) portfolios. That is, $\mathrm{RM}_{m}$ is replaced with $\mathrm{RSZ}_{i m}$, the monthly returns on a CRSP size-portfolio $i$ in month $m$, where $i=2,4,6,8$ and 10 .

The results relating to the reduced model are reported in Table B1 and the results relating to the full model are reported in Table B2. Our replication of both models leads to statistically significant estimates that are consistent with A02, as well as the findings we obtain using annual data. Specifically, $g_{1}>0$ and is strictly decreasing in firm size, while $g_{2}<0$ and is strictly increasing in firm size, which corroborates the in-sample hypothesis of a flight to liquidity. As with the annual measures of expected and unexpected market illiquidity, these results dissipate in the out-of-sample (Panel C) and full sample (Panel D) tests. While In MILLIQ $_{m-1}$ remains positive and decreases monotonically in company size, none of the coefficients are significant. Further, while the unexpected illiquidity term is negative and significant for both samples, the monotonic increase in $g_{2}^{i}$ is lost in the out-of-sample period. These findings indicate that, as with the annual estimates, the expected illiquidity measure does not induce a risk premium in a

\footnotetext{
${ }^{9}$ The required yield data, pertaining to Moody's seasoned BAA-rated and AAA-rated corporate bonds, are obtained from the Fed Economic Research database.

${ }^{10} \mathrm{~A} 02$ reports low correlations between the two bond yields and the illiquidity measure: Corr (ln MILLIQ $\left._{m}, \mathrm{DEF}_{m}\right)=-0.060$, Corr $\left(\ln \mathrm{MILLIQ}_{m}, \mathrm{TERM}_{m}\right)=0.021$ and Corr $\left(\mathrm{TERM}_{m}, \mathrm{DEF}_{m}\right)=0.068$. $^{2}$ Our replication over a matching sample period (1963 to 1996) finds these correlation coefficients to be $-0.009,-0.131$, and 0.300 , respectively. For the out-of-sample period (1997 to 2015), the coefficients are $0.058,-0.133$ and 0.335 , respectively. For the full sample period (1963 to 2015), the coefficients are $0.029,-0.204$, and 0.256 , respectively.
} 
share market that is more liquid, and the difference in the reaction between small and large companies to changes in unexpected illiquidity is no longer distinct. The inclusion of control variables in the regression generates largely insignificant coefficients and does not alter our overall findings. That is, the in-sample positive effects of the month of January and the default yield premium on ex ante stock returns disappear out-of-sample in the full model.

\section{Robustness Modifications}

To further our study of the effects of illiquidity on stock returns using the A02 measure, we repeat the cross-sectional tests (results from which are reported in Table 2) and the time-series tests (results from which are reported in Table 3) with the following robustness modifications to the published procedure. First, one of the filtering conditions requires sample stocks to have market capitalization data at the end of year $y-1$, in an effort to exclude derivative securities like ADRs, scores and primes. However, this condition still results in a sample with approximately $5 \%$ of securities that are not identified as common stocks by CRSP (CRSP share code $\geq 20$ ). Therefore, in our robustness tests, we exclude those observations where CRSP share code $\geq 20$. Second, we delete firm observations where the prior day return is missing as, in the event that the prior day price (and therefore return) is missing for a stock, CRSP uses the price up to ten days prior in its return calculation. This practice creates cumulative, as opposed to daily, returns that should not be present in an estimation of a daily illiquidity ratio. Third, in calculating the dividend yield, we use the stock price at the end of the second to last month to avoid the beginning of period price appearing on both sides of the cross-sectional model. This specification follows Brennan et al. (1998) who also calculate the dividend yield as a sum of all dividends paid over the previous 12 months, divided by the stock price at the end of the second to last month. Fourth, we replace the Durbin-Watson statistic in the time-series tests with the Durbin h-statistic as this metric is more appropriate when lagged dependent variables are included as explanatory variables in regressions (Durbin, 1970). Fifth, A02 trims firms located in the top and bottom 1\% of the distribution of the illiquidity measure for the cross-sectional tests, and firms located in the top $1 \%$ for the time-series tests. We replace trimming with winsorizing at the same cut-off levels. Sixth, we retain penny stocks in our sample, which are removed by A02 in the cross-sectional analysis. Finally, we adjust the ILLIQ measure for inflation in a manner consistent with Ben-Rephael et al. (2015). Specially, we use the following measure:

$$
\text { ILLIQ_ADJ }_{i y}=\frac{1}{D_{i y}} \sum_{t=1}^{D_{i y}} \frac{\left|R_{i y d}\right|}{\mathrm{VOLD}_{i y d} \cdot \mathrm{INF}_{y d}}
$$


where $\mathrm{INF}_{y d}$ is an adjustment factor to express dollar volume in real terms using the CPI at the end of 2015 , calculated as $\mathrm{CPI}_{y m} / \mathrm{CPI}_{\mathrm{Dec}-15} .{ }^{11}$ The analysis with these seven robustness modifications is conducted over the full period (1964 to 2015) to maximize the sample size and increase the power of our tests.

The results that incorporate these robustness measures are presented in Table 4. The cross-sectional results (Panel A) indicate that the illiquidity measure remains positive and significant, but the magnitude of the coefficients has further reduced for all specifications. When using the full model, the mean of the ILLIQMA coefficient over the full sample is 0.060 , compared to 0.079 over the same period pre-robustness, and 0.112 in A02. While the other variables also exhibit changes in magnitude in comparison to prior findings (reported in Table 2 Panel C), the overall interpretation remains consistent. Past returns, $\mathrm{R} 100_{i y}$ and $\mathrm{R} 100 \mathrm{YR}_{i y}$, are both positive and significant, consistent with A02. SDRET $i y$ and DIVYLD $i y$ retain their negative coefficients.

The time-series results (Panel B) are also similar to our prior findings over the full sample period (reported in Table 3 Panel D). The $g_{1}$ estimates are strictly decreasing in firm size, but lack significance. The $g_{2}$ estimates are negative, significant and strictly increasing in firm size, but they are the product of a sample primarily from an era that did not include innovations in technology and decimalization of security prices that have both caused a substantial increase in liquidity over the last two decades. In terms of magnitude for both the expected and unexpected illiquidity variables, all coefficients are again below their prerobustness equivalents. The robust model displays similar explanatory power and autocorrelation of the residuals as model (3).

In addition to the abovementioned robustness, we also consider whether the slope coefficients pertaining to the expected $\left(g_{1}^{i}\right)$ and unexpected $\left(g_{2}^{i}\right)$ illiquidity factors in the time-series regressions are statistically different from each other across the considered size (decile) portfolios. That is, $g_{1 \text { or } 2}^{2}$ is compared to $g_{1 \text { or } 2}^{4}, g_{1 \text { or } 2}^{4}$ is compared to $g_{1 \text { or } 2}^{6}$ and so on. The findings of these two-sample $t$-tests with a null hypothesis of zero difference are reported in Table B3. The results for the in-sample (Panel A) and out-of-sample (Panel B) tests indicate no statistically significant difference between the loadings on adjoining size portfolios. The comparisons have to be stretched to considerations between $g_{1 \text { or } 2}^{2}$ (portfolio RSZ ${ }_{2}$ ) and $g_{1 \text { or } 2}^{6}$ (portfolio RSZ ${ }_{6}$ ) or $g_{1 \text { or } 2}^{6}$ and $g_{1 \text { or } 2}^{10}$ (portfolio $\mathrm{RSZ}_{10}$ ) to return significant differences between the slopes of the size portfolio estimates. However, if the $t$-tests are conducted over the full sample period of the annual observations (Panel C and Panel D), where the increased sample size

\footnotetext{
${ }^{11}$ Our CPI data are the seasonally adjusted monthly Consumer Price Index for All Urban Consumers: All Items (CPIAUCSL), obtained from the Federal Reserve Bank of St. Louis Economic Research database. As CPI data are available at a monthly, as opposed to daily, frequency, we take CPI for each day as the CPI in the month to which the day belongs.
} 

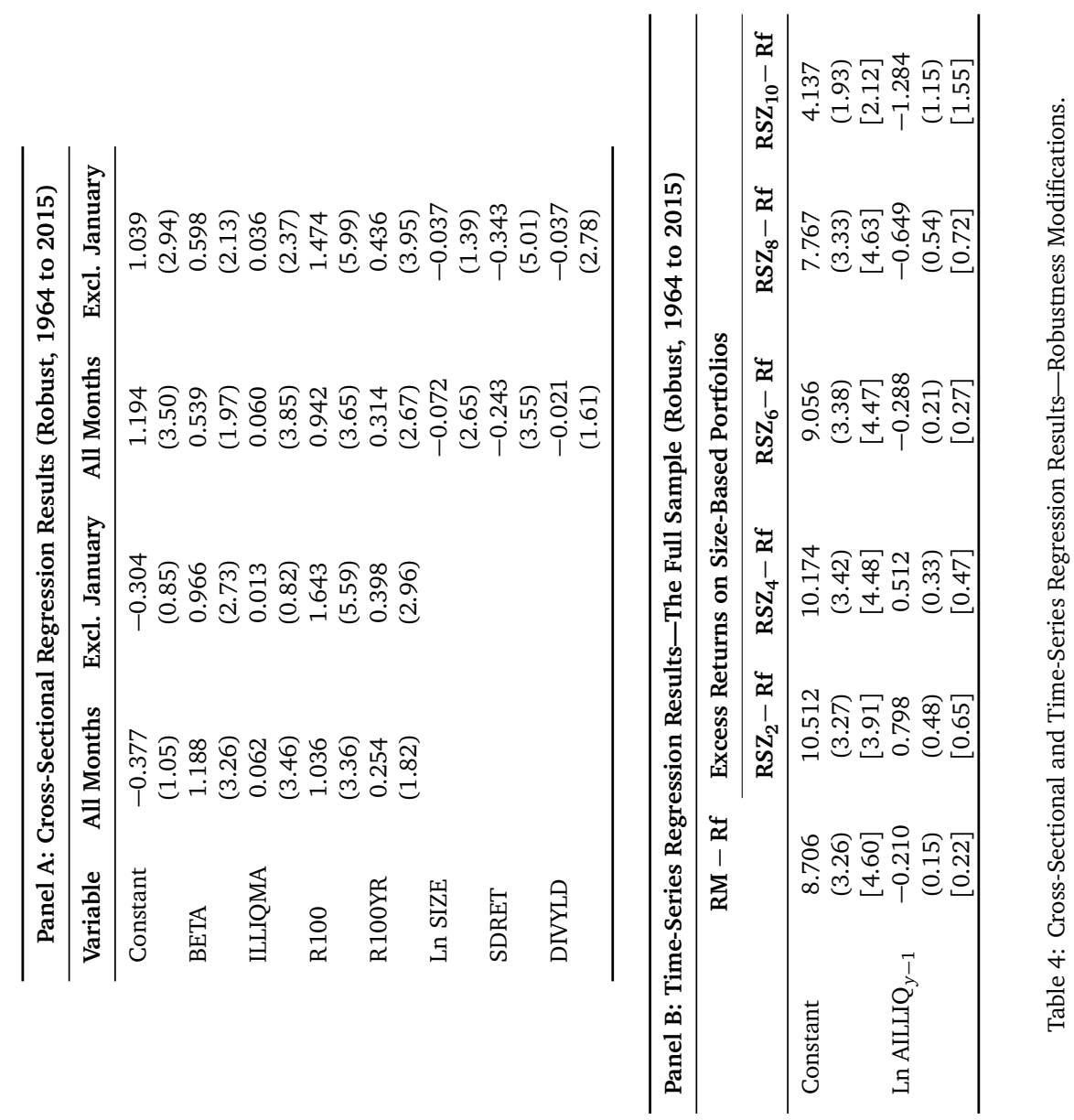


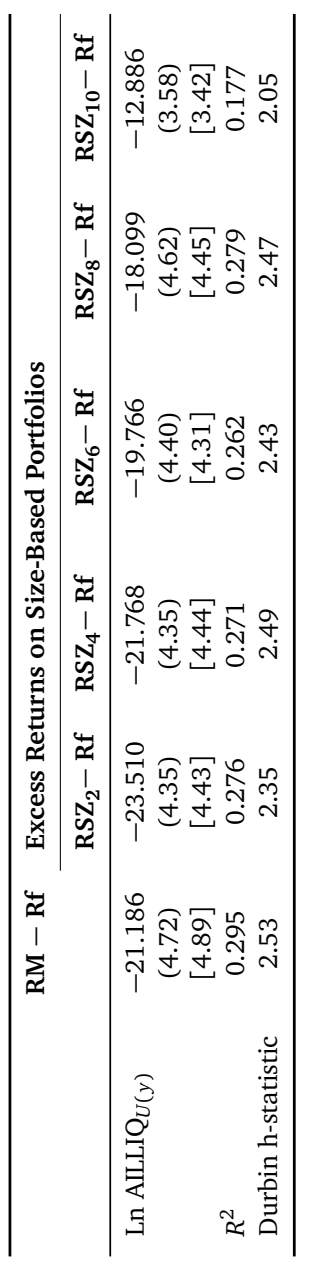

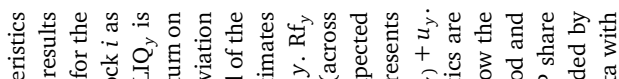

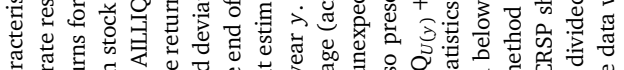

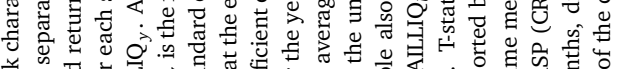

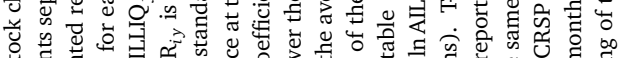

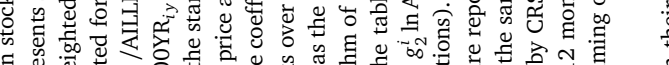
б

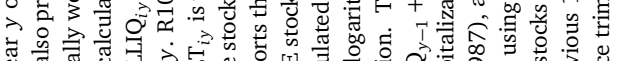

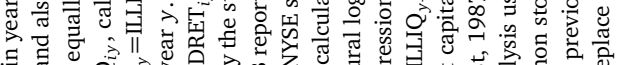

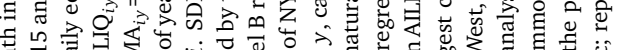

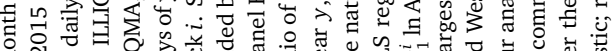

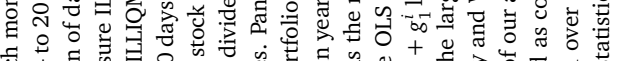

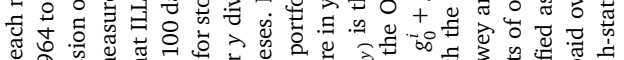

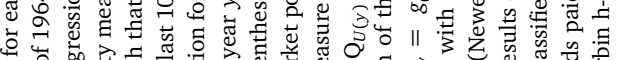

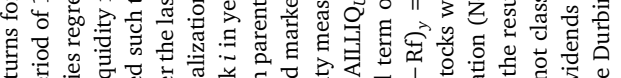

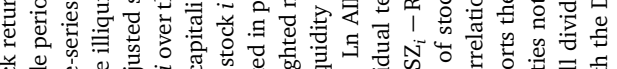

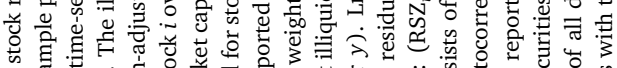

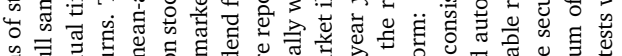

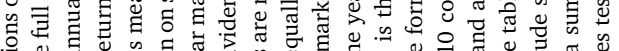

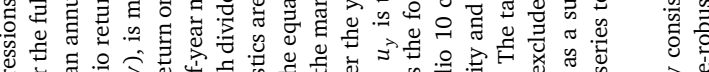

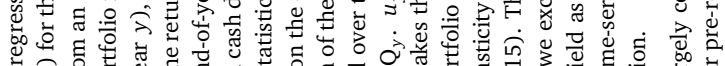

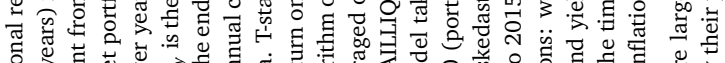

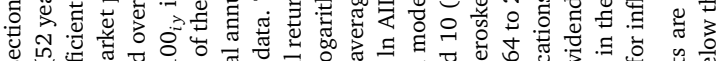

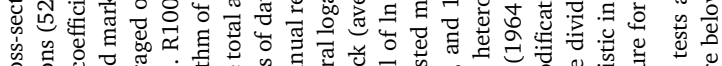

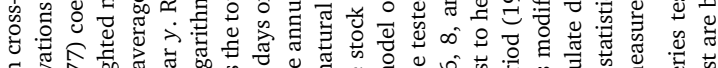
๑

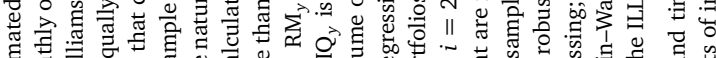

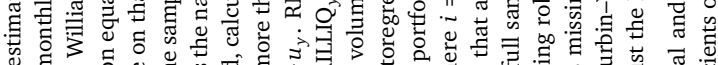

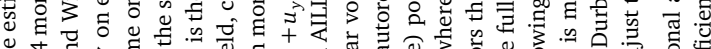

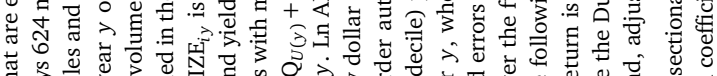

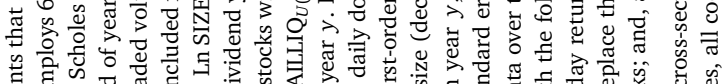

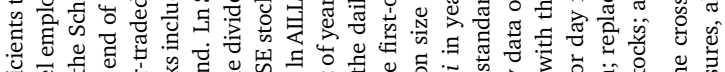

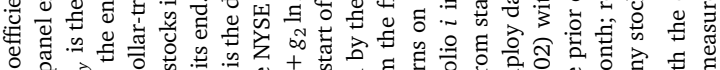

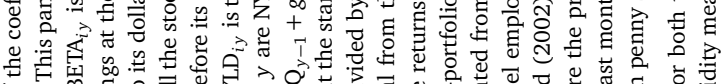

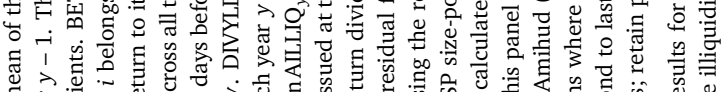

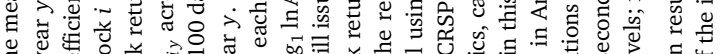

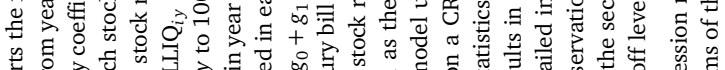

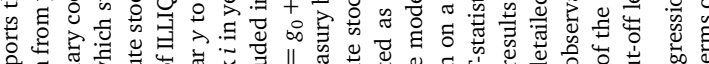

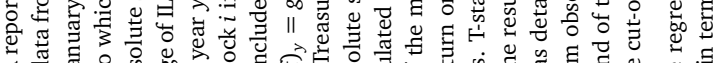

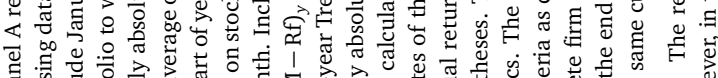

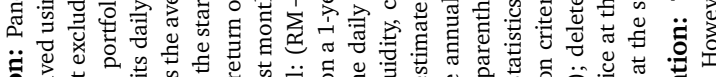

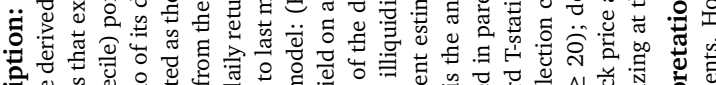

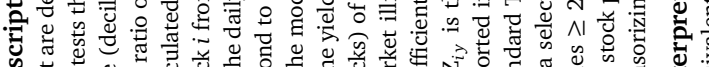

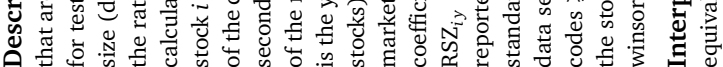


amplifies the statistical power of the empirics, the significance of coefficient differences improves for the majority of tests. This occurs despite the magnitude of the difference typically decreasing, a reflection of lower standard errors ${ }^{12}$ in generating $t$-values. The statistical differences between the expected and unexpected illiquidity loadings for the adjoining portfolios are most pronounced when comparing portfolios $\mathrm{RSZ}_{8}$ and $\mathrm{RSZ}_{10}$, as portfolio ten contains stocks with the largest capitalizations and, consequently, little illiquidity concern from investors.

\section{Further Discussions of Illiquidity}

\subsection{Discussion of the Illiquidity Metric}

Central to the interpretation of A02 is the validity of the illiquidity measure ILLIQ, calculated as the ratio of the daily absolute stock return to its dollar-traded volume, averaged over the number of days for which data are available in year $y$. In the time since publication of A02, ILLIQ has become an established gauge of illiquidity in the literature (see, e.g., Acharya and Pedersen, 2005; Hasbrouck, 2009; Korajcyzk and Sadka, 2008). Nonetheless, it is important to consider alternative interpretations for the measure.

The numerator of ILLIQ comprises the absolute value of daily stock returns. A number of studies (Elandt, 1961; Leone et al., 1961) demonstrate that the volatility of an estimate can be gauged from the sum of its absolute values. Further, a separate body of literature shows a positive intertemporal relation between expected stock returns and stock market volatility (French et al., 1987; Merton, 1980). As A02 acknowledges and controls for in cross-sectional tests, it is therefore possible that the ILLIQ measure instead captures the effect of stock market volatility on expected stock returns.

To further test the association between the A02 illiquidity measure and stock volatility, we perform the following cross-sectional regression for the year 1984:

$$
\mathrm{ILLIQ}_{i}=\alpha+\beta \mathrm{VOL}_{i}+u_{i}
$$

where $\mathrm{VOL}_{i}$ is the standard deviation of daily returns for stock $i$. This mirrors the cross-sectional test estimated by A02 for the same year, in which ILLIQ is regressed on two liquidity variables from the microstructure literature, specifically Kyle's (1985) $\lambda$ and the fixed cost portion of the bid-ask spread $\psi$. A02 finds ILLIQ to have a positive relation with $\lambda(t=13.78)$ and $\psi(t=17.33)$, with $R^{2}=0.30$, taken as evidence of the validity of ILLIQ as a gauge of stock illiquidity. Our estimation of Eq. (8) yields a parameter estimate for $\beta$ of $4.53(t=4.84)$ with

\footnotetext{
${ }^{12}$ The average pooled standard error for the conducted two-sample $t$-tests with respect to the expected (unexpected) illiquidity slope coefficient differences is 1.523 (2.822) in Panel A, 1.615 (5.374) in Panel B, 0.299 (1.701) in Panel C and 0.145 (1.511) in Panel D.
} 
$R^{2}=0.02$. While this is substantially lower than the equivalent statistics A02 finds for the $\lambda$ and $\psi$ metrics, it is nonetheless significant.

To extend this analysis, we perform the same test, but replace ILLIQ with its numerator, namely the sum of the absolute values of an individual stock's returns over a given year. This provides a more direct examination of whether the A02 illiquidity metric is in part a proxy for stock return volatility, by reducing the metric to its return component. Consistent with the findings of Leone et al. (1961) and Elandt (1961), this adjustment yields much stronger results, with a parameter estimate for $\beta$ of $166.53(t=135.97)$ with $R^{2}=0.93$.

Therefore, the test used by A02 to argue that ILLIQ is a valid measure of illiquidity can also be employed to suggest that ILLIQ is instead a plausible metric for detecting the return premium required by market participants for stock volatility, particularly if results are driven by the ILLIQ numerator. As such, the findings in A02 could be seen as corroborating evidence for the literature that documents a positive time-series relationship between stock volatility and ex ante returns, as opposed to providing new evidence of a time series relation between expected liquidity and ex ante returns.

To gain further insight into the effect driving the output, we therefore examine an adjusted illiquidity metric, in which the absolute value of returns is removed to leave only the dollar-traded volume. As dollar volume (VOLD) is a more intuitive gauge of a stock's liquidity than its volatility, this adjustment provides an alternative measure of illiquidity that is not exposed to the issues stemming from the dual interpretation of the ILLIQ numerator.

We therefore perform the same regressions using only dollar volume as follows:

$$
(\mathrm{RM}-\mathrm{Rf})_{y}=g_{0}+g_{1} \ln \operatorname{AINVVOLD}_{y-1}+g_{2} \ln \operatorname{AINVVOLD}_{U(y)}+u_{y}
$$

where AINVVOLD ${ }_{y}=1 / N_{y} \sum_{t=1}^{N_{y}} \operatorname{INVVOLD}_{i y}, \operatorname{INVVOLD}_{i y}=1 / D_{i y} \sum_{t=1}^{D_{i y}} 1 /$ VOLD $_{i y d}$ and the remaining variables are as defined in A02. Higher values of INVVOLD represent greater illiquidity, and therefore the coefficients can be interpreted in a consistent fashion to ILLIQ. As reported in Table 5, the results using AINVVOLD are analogous to those generated using AILLIQ. This suggests that it is the denominator of AILLIQ that is driving the results, namely the dollar-traded volume. As dollar volume is a natural measure of liquidity, this finding adds weight to the interpretation by A02 of the existence of a priced illiquidity risk factor, although the premium has declined substantially post-publication.

In recent research related to this line of enquiry, Lou and Shu (2016) find results that are consistent with ours and similarly identify the trading volume component of the A02 measure as the reason why the original return-to-volume ratio is priced. Whereas we focus our attention on the changing magnitudes of the expected and unexpected illiquidity factors in the time-series and their monotonic properties with respect to size portfolios, however, Lou and Shu (2016) concentrate most of their analysis on decomposing the A02 measure to examine its pricing. In doing 


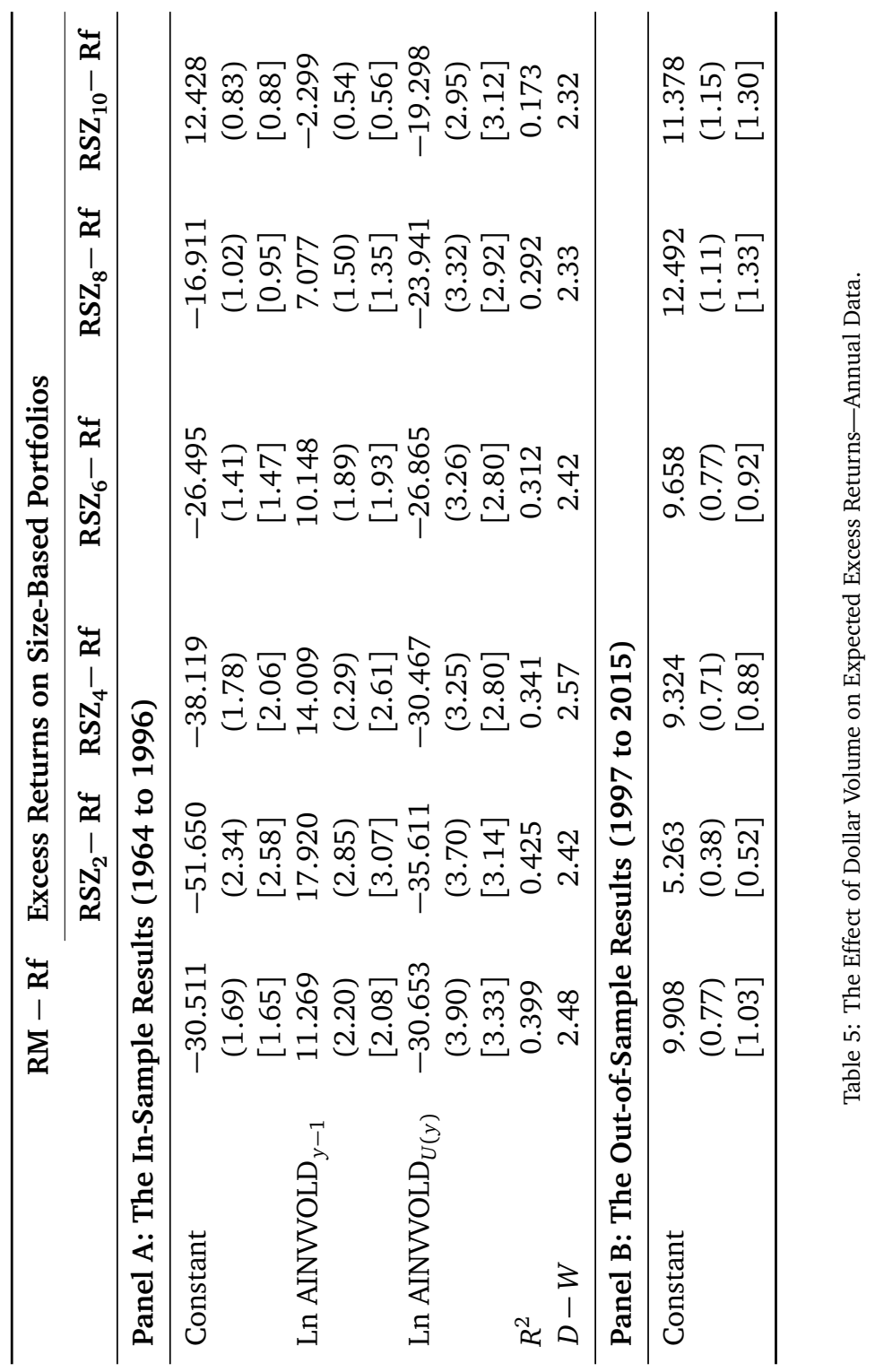




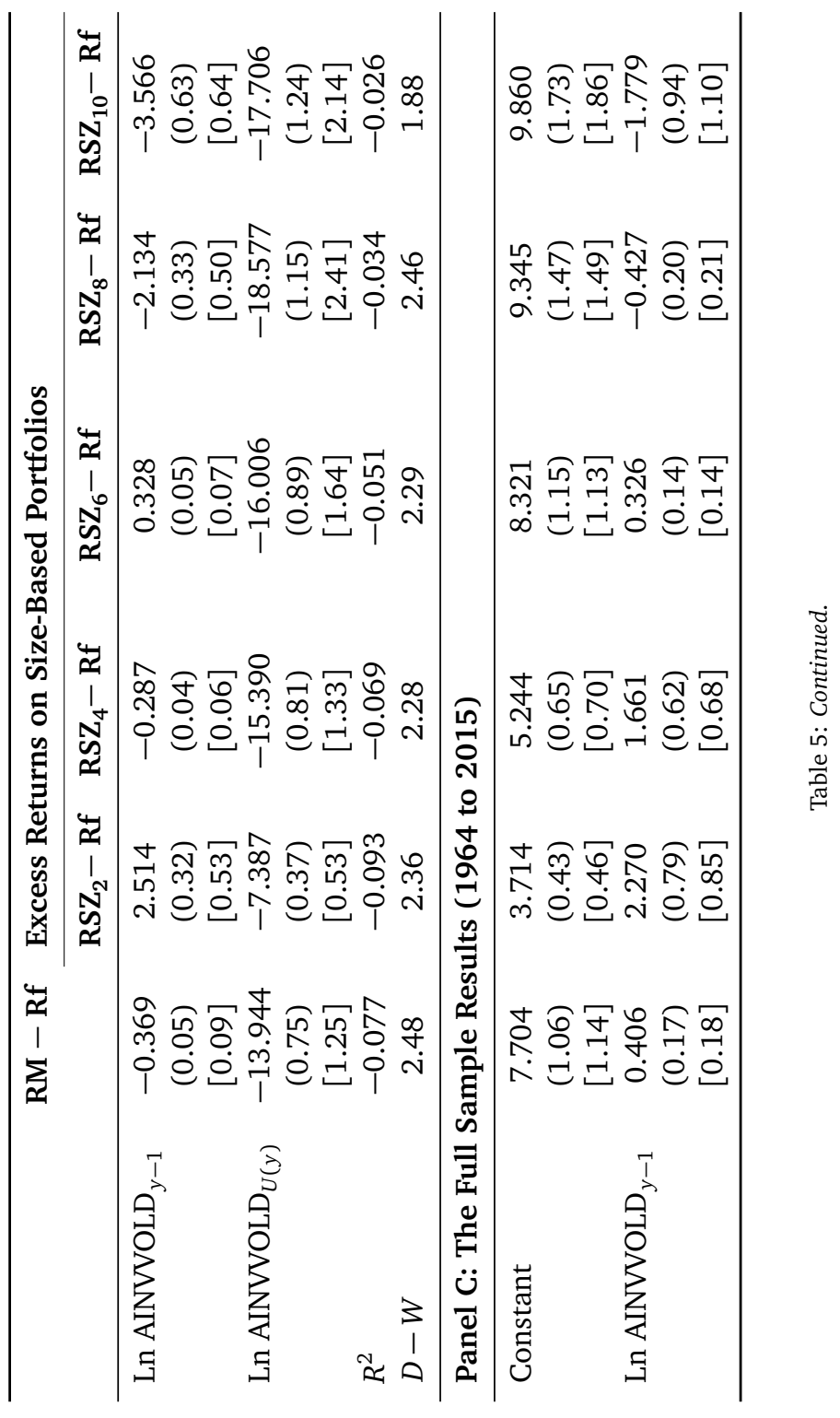




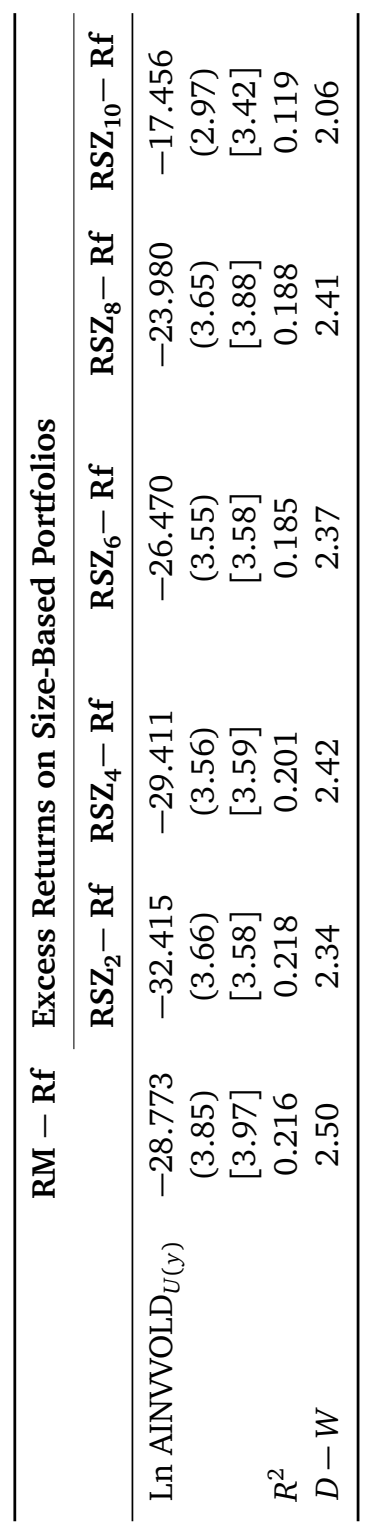

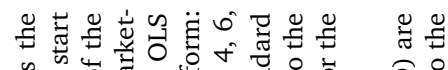

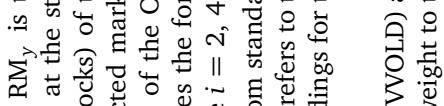

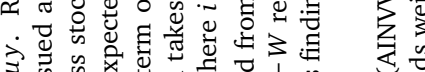

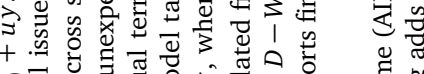

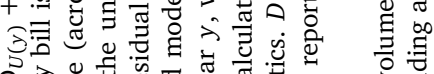

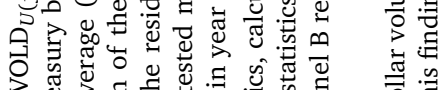

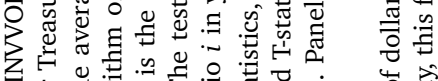

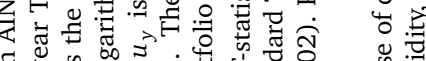

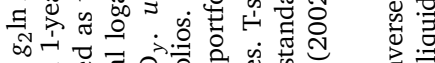

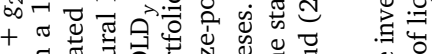

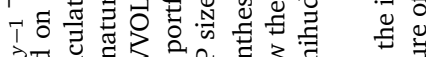

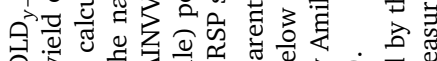

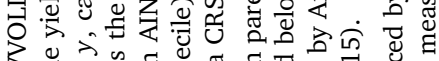
j).

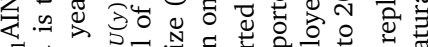

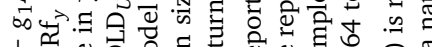

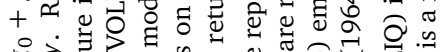

نे 川

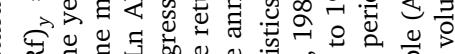

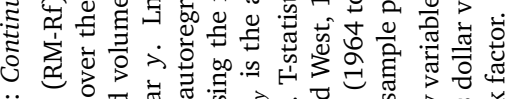

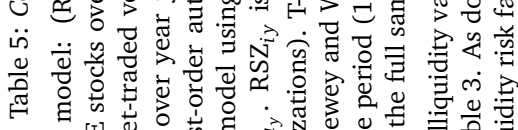

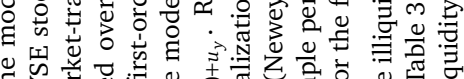

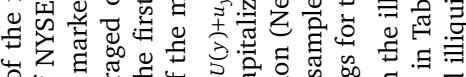

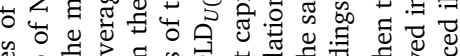

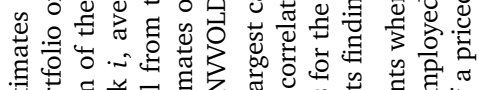

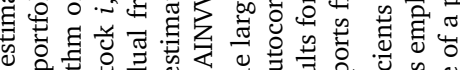

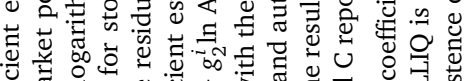

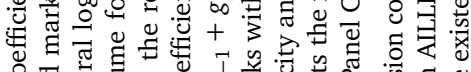
ठ

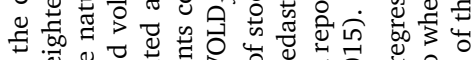

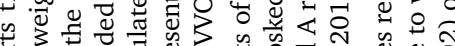

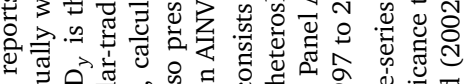

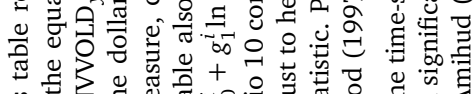

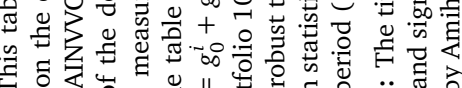

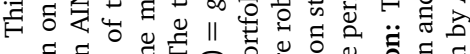
其5

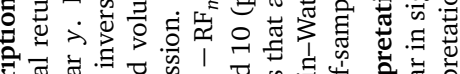

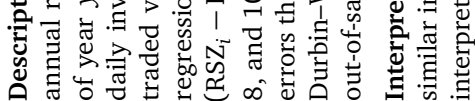


so, they find that the return premium associated with the measure disappears once the volume component, that exhibits significantly greater cross-sectional variation compared to the stock return component, is withdrawn. Their further tests show that the pricing of the A02 measure, generally considered a liquidity proxy that compensates for price impact by the literature, is not explained by common high-frequency price impact and spread benchmarks. The study finds that the significance of the trading volume component is due, not to the liquidity premium, but to the mispricing (non-liquidity) hypothesis stemming from corrections to overly optimistic expectations about high volume stocks relative to low volume stocks following high market sentiment periods and earnings announcements.

In addition to the findings of Lou and Shu (2016), support for the mispricing hypothesis is offered by a number of prior studies. For example, Baker and Wurgler (2006) employ share turnover to construct their investor sentiment measure and demonstrate that it has significant cross-sectional effects. Specifically, stocks that are attractive to optimists and, at the same time, unattractive to arbitrageurs earn low returns following high sentiment (high turnover) periods relative to low sentiment periods. That is, high turnover forecasts low market returns due to systematic patterns of mispricing correction, a result confirmed by Lou and Shu (2016). Barinov (2014) shows that in asset pricing tests, liquidity as well as liquidity risk measures are unable to explain why higher turnover predicts lower future returns. Instead, the author argues that turnover reflects firm-specific uncertainty rather than liquidity, and high turnover (uncertainty) firms tend to outperform their less uncertain peers when expected aggregate volatility increases. That is, high turnover firms are subject to lower subsequent returns because their (relatively) higher idiosyncratic uncertainty makes them a hedge against aggregative volatility risk, rather than because they attract a lower liquidity (or turnover) premium. Thus, in contrast to trading volume acting as a liquidity proxy, these papers point to non-liquidity factors as explanations for the significance of the volume premium in the data.

\subsection{K-Fold Cross-Validation: Illiquidity Premium Change Point}

In our main results, we show that the sensitivity of investors to market illiquidity risk has declined since the publication of A02. This finding is consistent with a number of aforementioned technological innovations and regulatory changes in the years immediately following the study, that have significantly enhanced share market liquidity by facilitating the trade process and reducing its costs. To assess more formally whether the end of the A02 sample period could be deemed a significant change point in the market's demand for an illiquidity premium, we perform a $k$-fold cross-validation study. We treat the A02 sample period (33 years, 1964 to 1996) as a training set in which the coefficients in A02 Eq. (10) are estimated and fitted to a test set comprising post-publication data (19 years, 1997 to 2015), producing a mean absolute error between the fitted and actual values for 
the independent variable (RM - Rf). We then perform 1,000 simulations in which, for each simulation, the same proportion of observations (19 years, or $36.5 \%$ of the data) are randomly sampled with replacement from the full 1964 to 2015 period and allocated to a simulation test set. The same fitting process is used for the simulation training and test sets, resulting in a mean absolute error for each simulation.

We then calculate the proportion of the 1,000 simulated mean absolute errors, one for each cross-validated instance, which are below the mean absolute error from the fitted post publication sample. If the end of the A02 sample signifies a change point in the illiquidity premium environment, the cross-validation procedure will randomly pick elements from before and after the change point, effectively smoothing over the change point within the modelling process. As a result, the majority of the mean absolute errors from the simulations would fall below that from the post publication test period. Consistent with this, we find that only $16.9 \%$ of the mean absolute errors from the simulations exceed that from the post-publication sample, providing further evidence of a change in investor attitudes towards illiquidity risk in the past two decades.

\section{Conclusion}

In this paper, we show that the findings of $\mathrm{A} 02$ can be replicated using the same sample period, method, and data selection criteria as detailed in the seminal study. The employed measure of expected illiquidity has a positive and significant effect on ex ante stock returns while unexpected illiquidity has a negative and significant effect on contemporaneous stock returns. These effects are monotonically stronger for smaller, and therefore less liquid, stocks, reflective of a flight to liquidity by investors.

However, in out-of-sample tests, these results dissipate. Both the expected and unexpected market illiquidity time-series measures lose their monotonic nature in regard to firm size, with the expected illiquidity coefficients also becoming statistically insignificant for all specifications. This indicates a decline in the sensitivity of investors to illiquidity risk, a likely reflection of the significant expansion of equity trading over the last two decades. Further robustness in the form of extra data filters and alternative test specifications, designed to extend the original study, corroborate these findings.

We assess alternative interpretations of the employed illiquidity measure and consider whether ILLIQ could instead be capturing the effect of stock market volatility on expected returns. However, we ultimately conclude that the denominator of the illiquidity ratio, dollar-traded volume, is driving the results reported in the seminal study. That is, employing the inverse of the dollar-traded volume in the same manner as ILLIQ leads to analogous findings in terms of sign, magnitude and statistical significance as those reported in A02. 
Finally, we perform a $k$-fold cross-validation study in an effort to confirm a change point in the illiquidity premium. That is, we treat the A02 sample period (33 years, 1964 to 1996) as a training set in which regression coefficients are estimated and fitted to a test set comprising post-publication data (19 years, 1997 to 2015), producing a mean absolute error between the fitted and actual values for the excess return time-series. We find that the mean absolute error from the post publication sample exceeds all but $16.9 \%$ of those from the simulations, confirming a change in the sensitivity of market participants to illiquidity risk over the past 20 years.

\section{Appendix A}

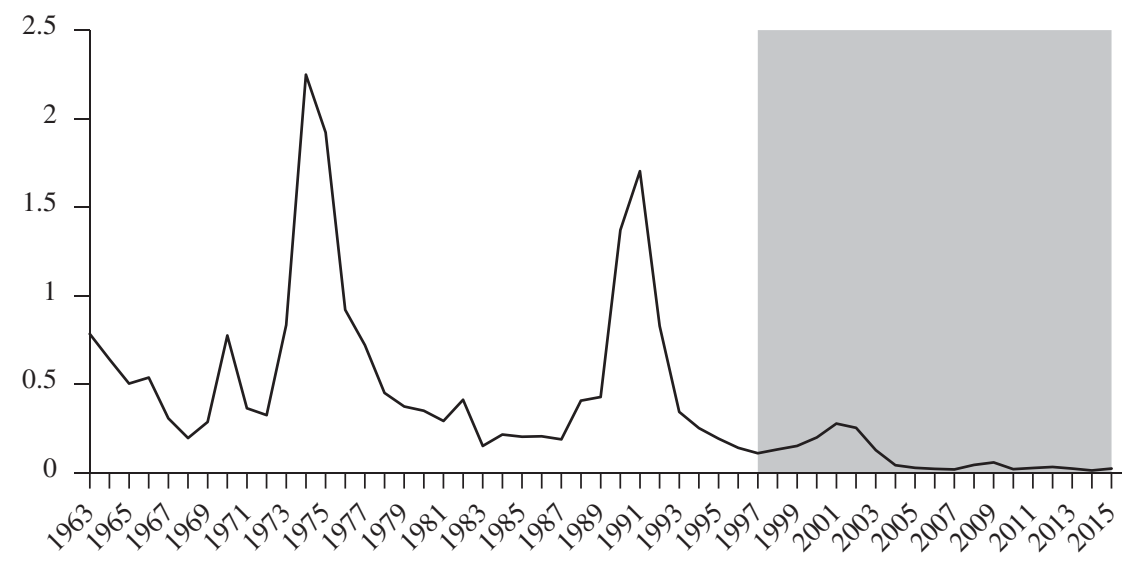

Figure A1: Time-Series Plot of AILLIQ $y$ (1963 to 2015).

Description: This figure presents a time-series plot of the annual market illiquidity measure, AILLIQ ${ }_{y}$, calculated as the average (across the sample stocks) of the daily absolute stock return divided by the daily dollar volume of the stock (averaged over the year $y$ ). The plot spans the full sample period of our study (1963 to 2015). The Amihud (2002) sample spans the period 1963 to 1997. The shaded area represents the illiquidity measure post publication, 1997 to 2015.

Interpretation: The plot shows a considerable reduction in the magnitude of the market illiquidity measure over the last two decades, with its values persistently close to zero post 2003. 


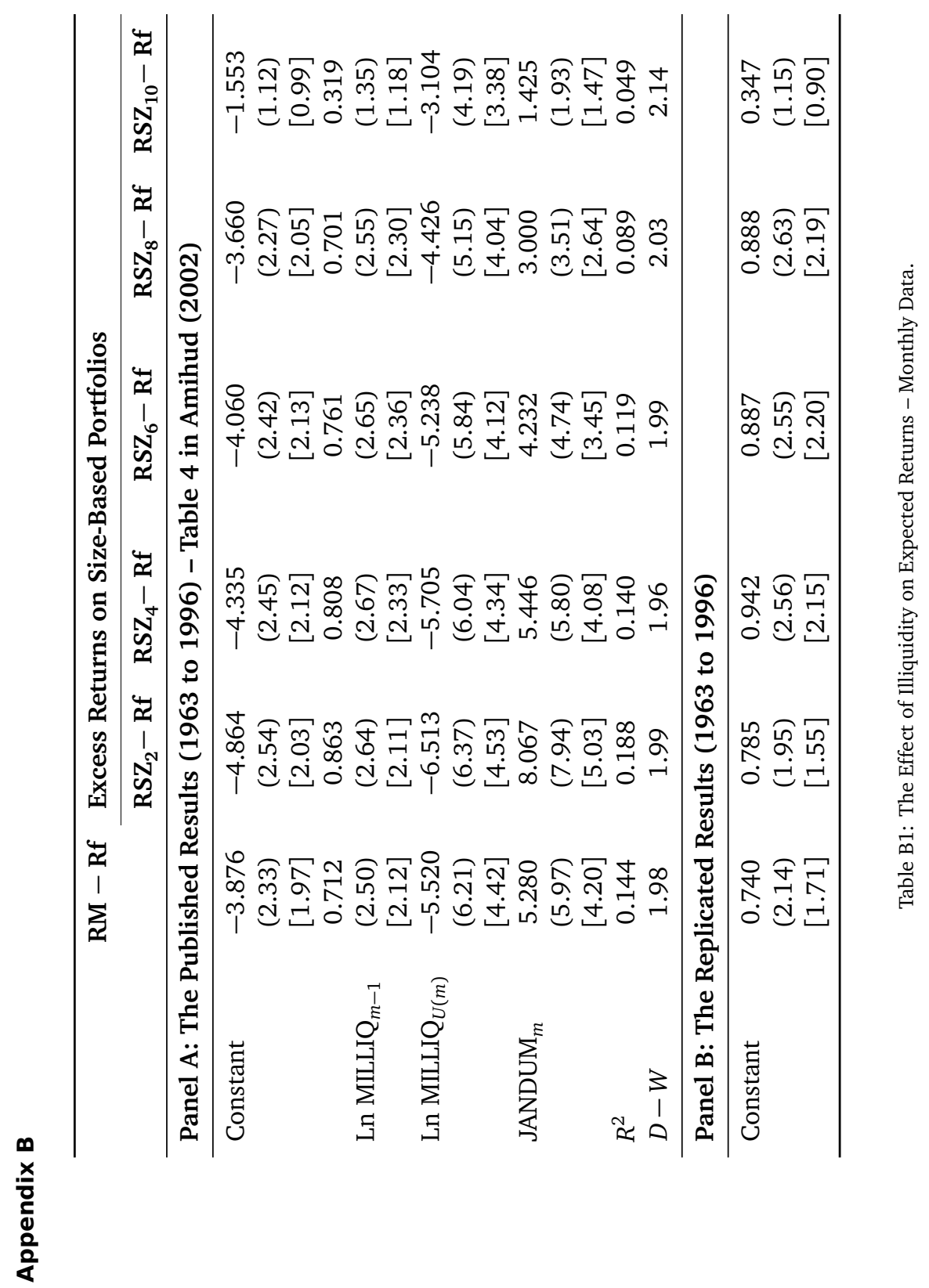




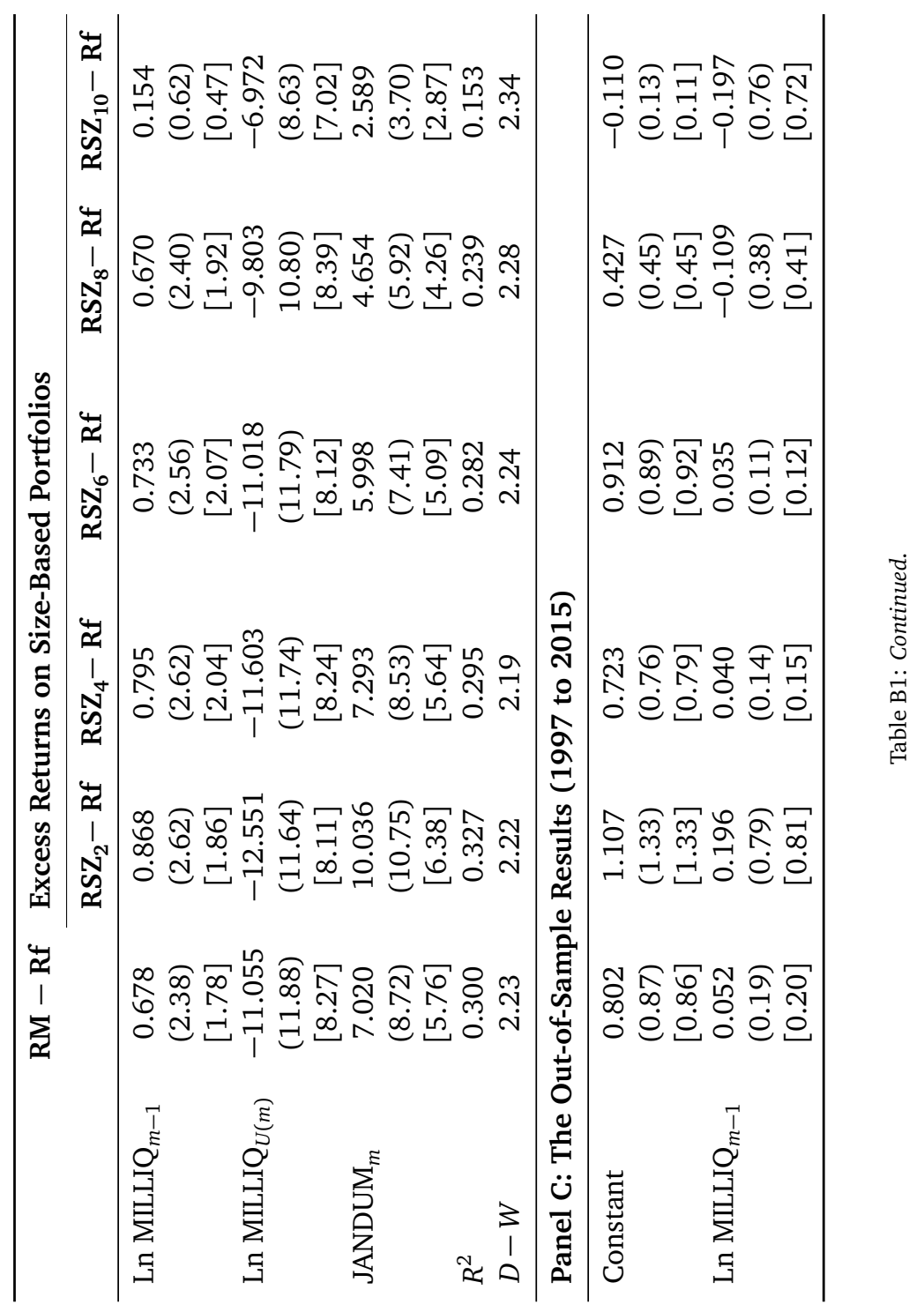




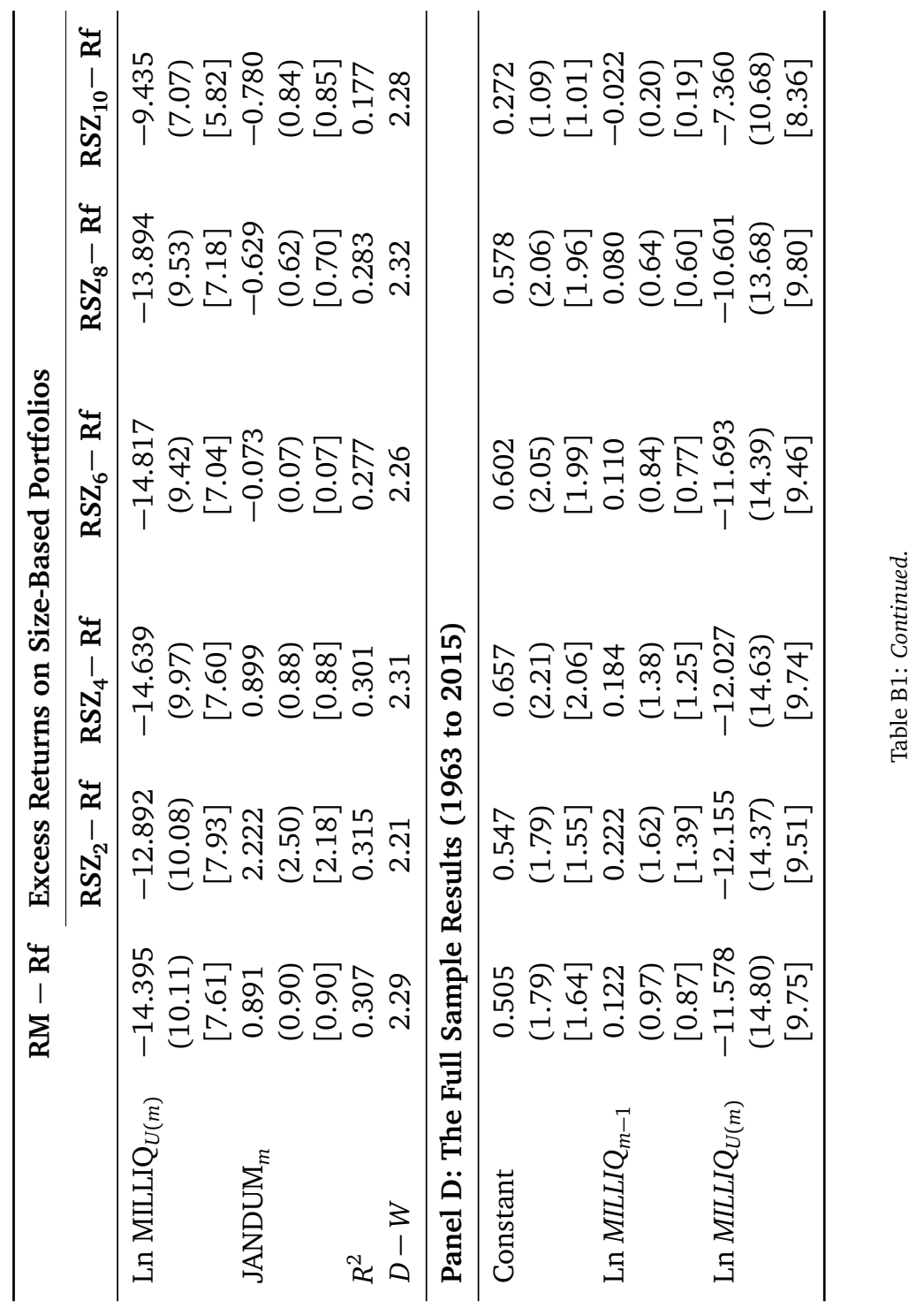




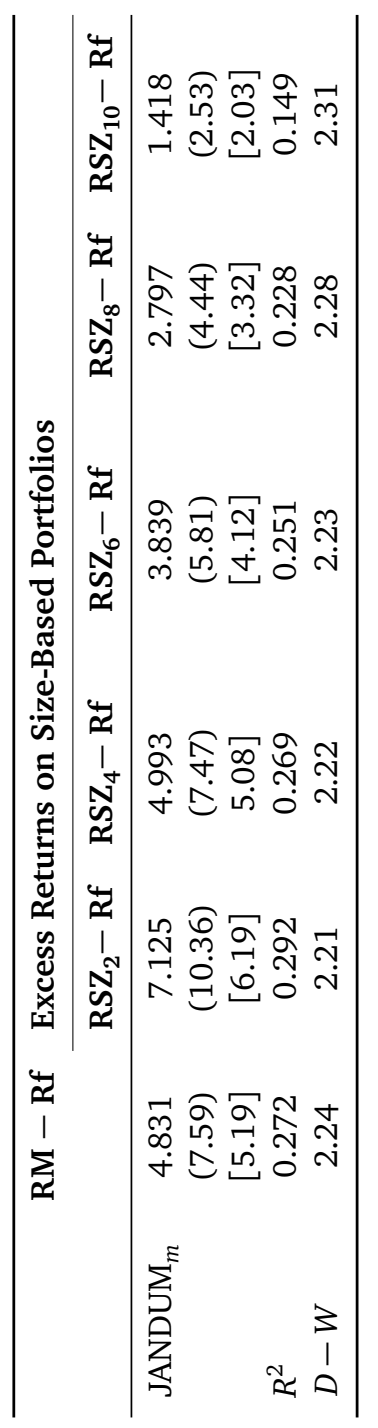

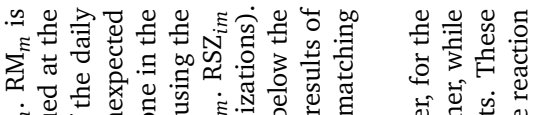

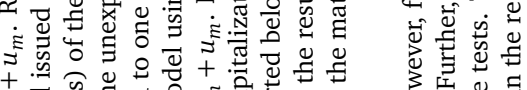

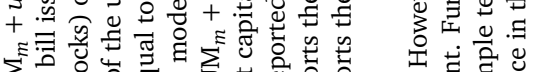

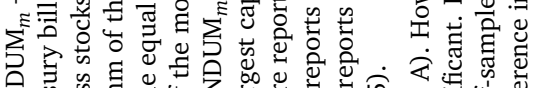

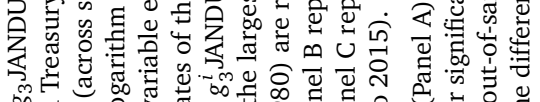

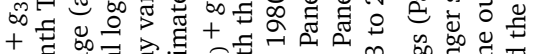

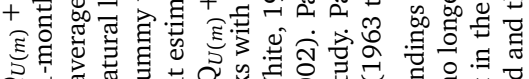

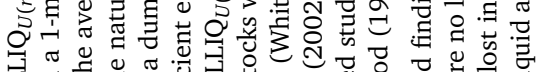

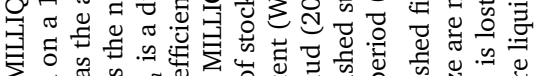

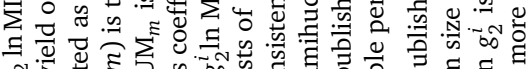

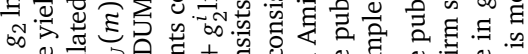

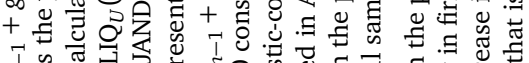

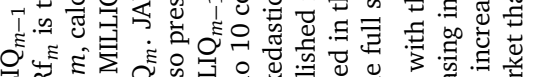

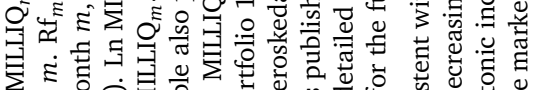

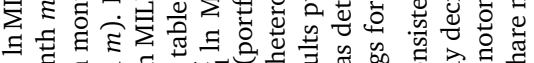

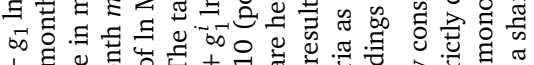

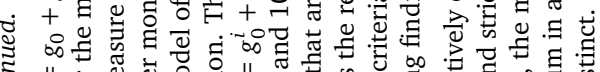

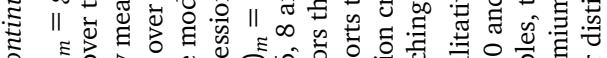

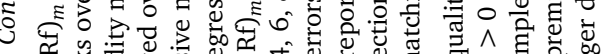

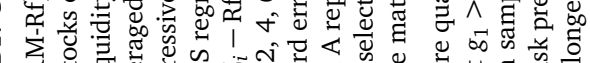

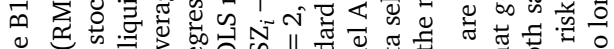

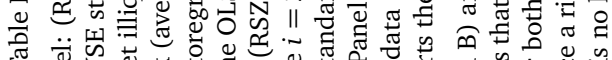

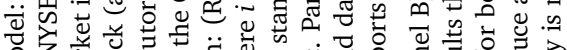

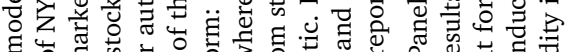

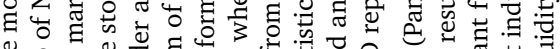

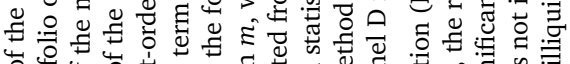

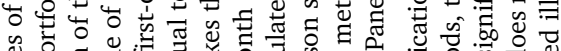

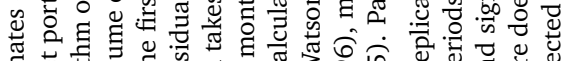

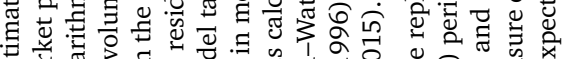

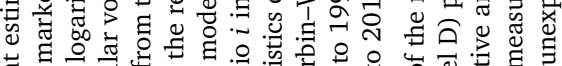

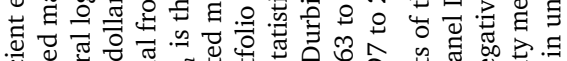

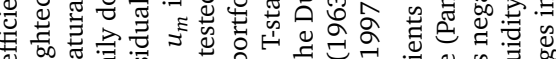

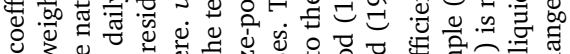
3 0 声.

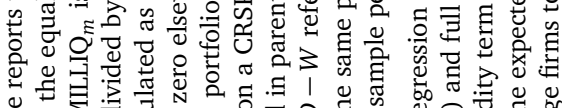

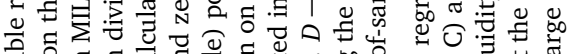

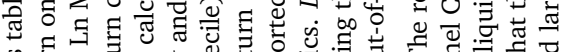

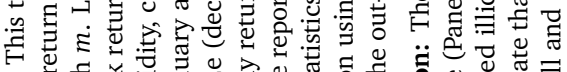

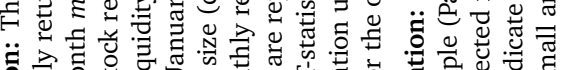

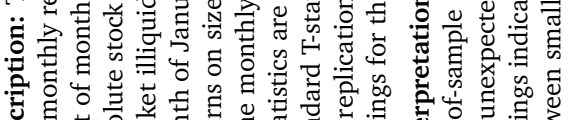

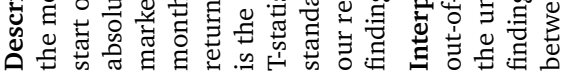




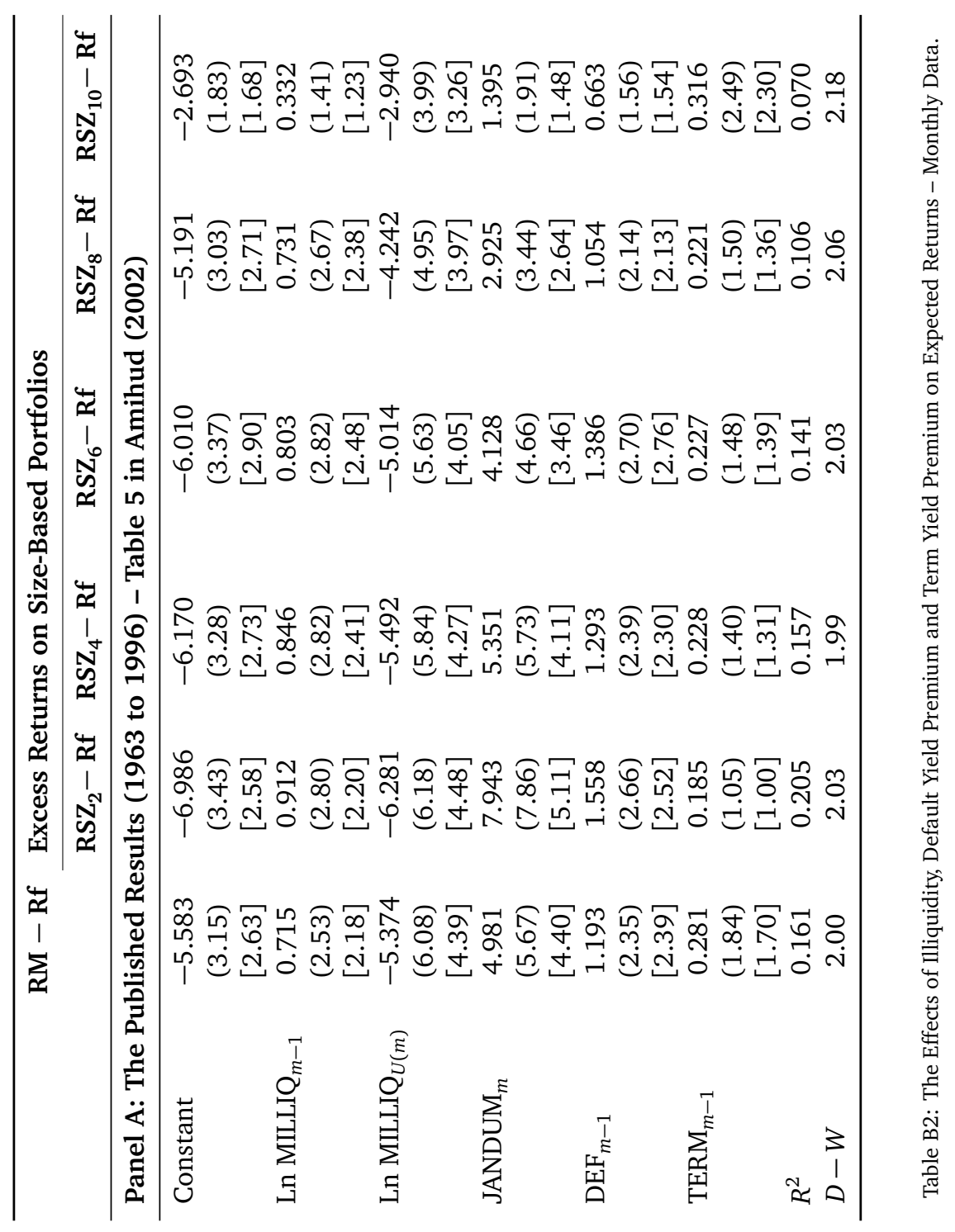




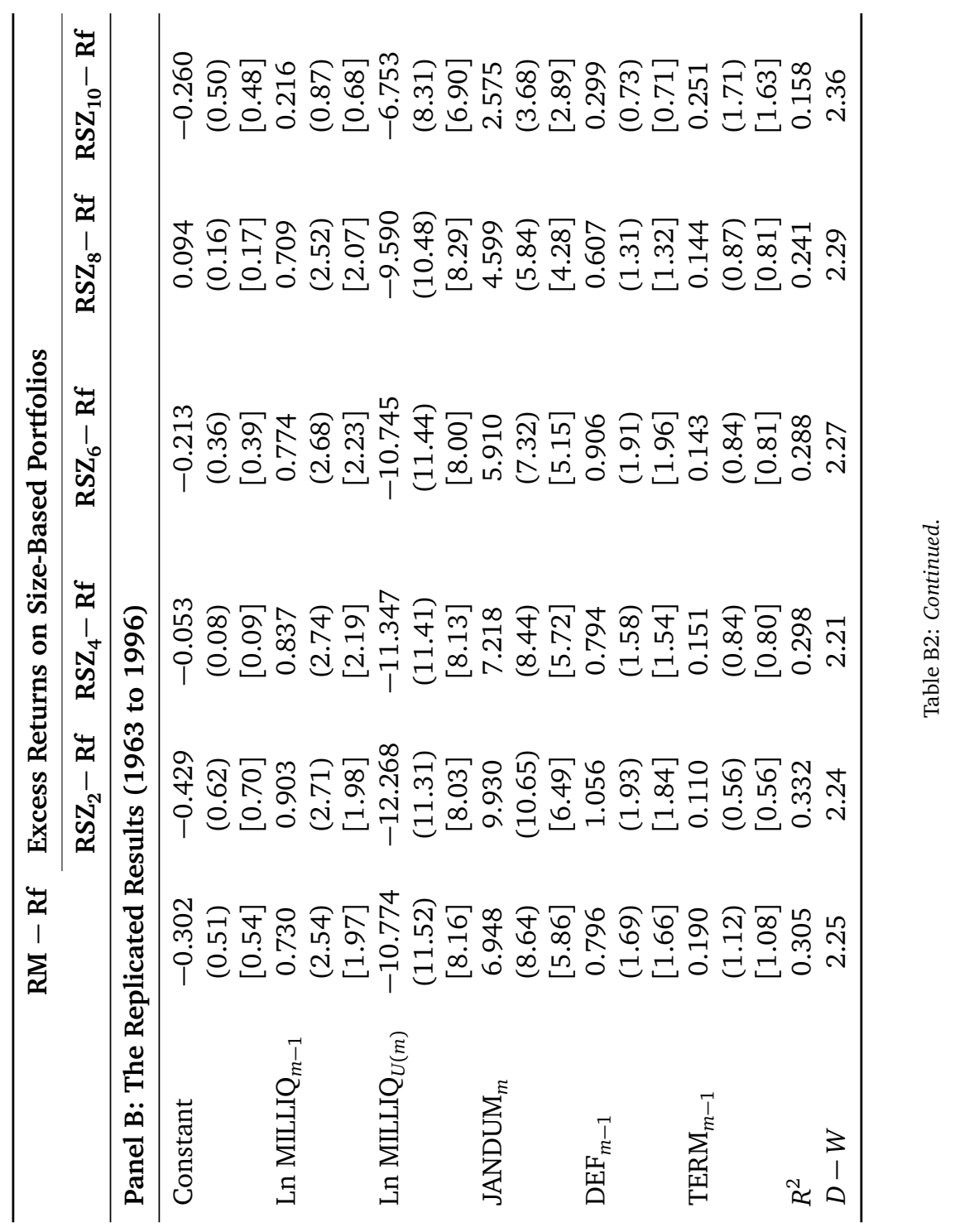




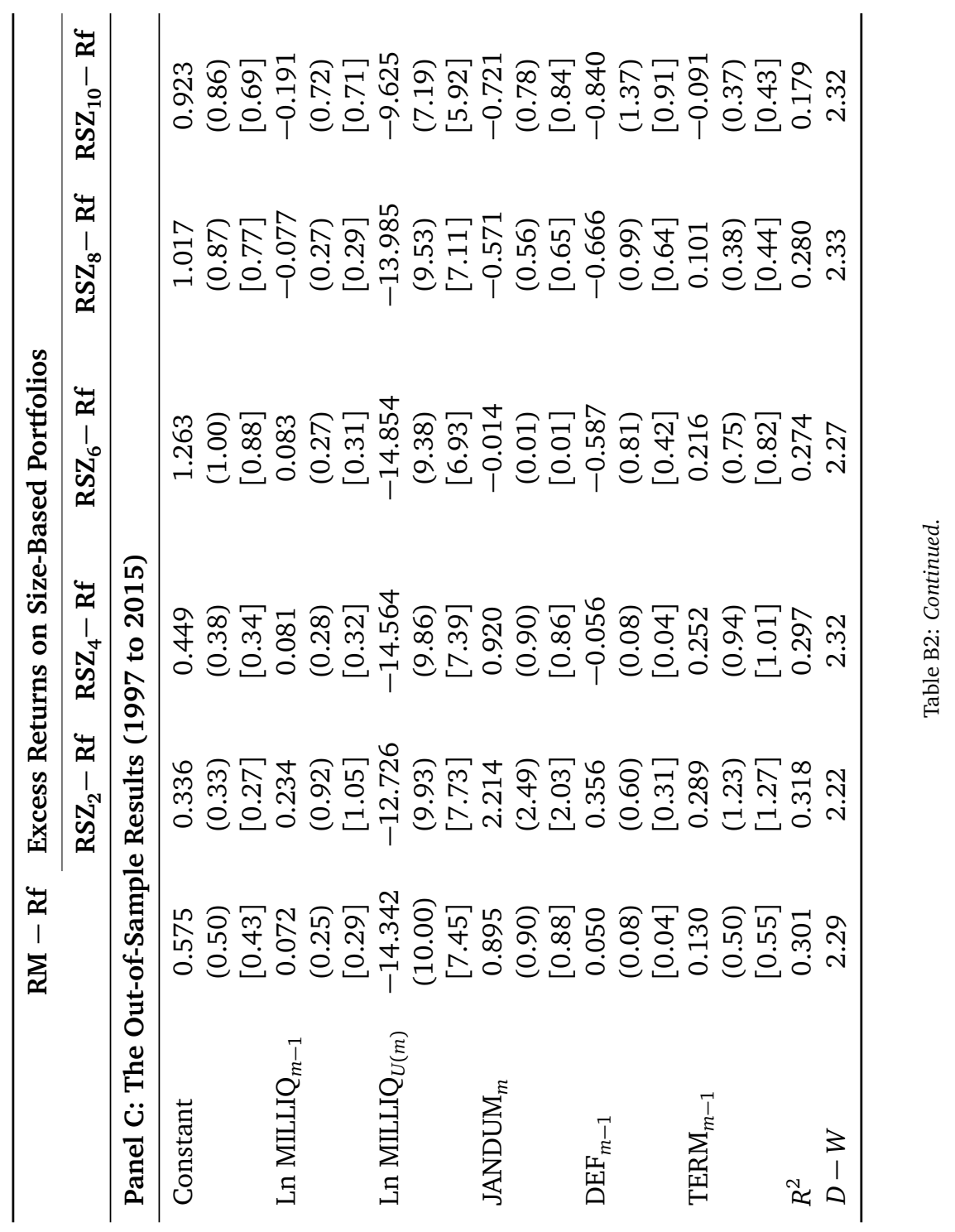




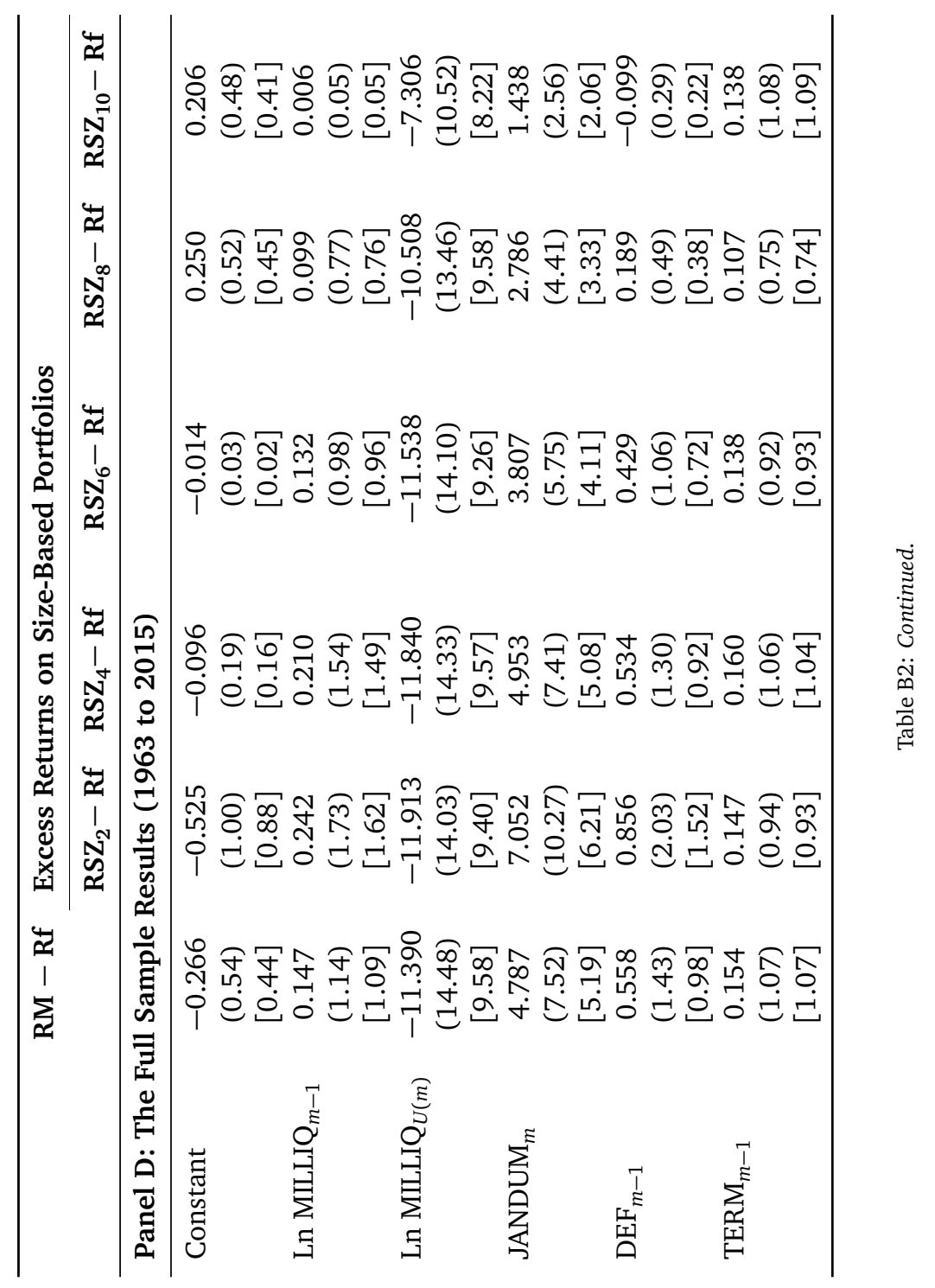




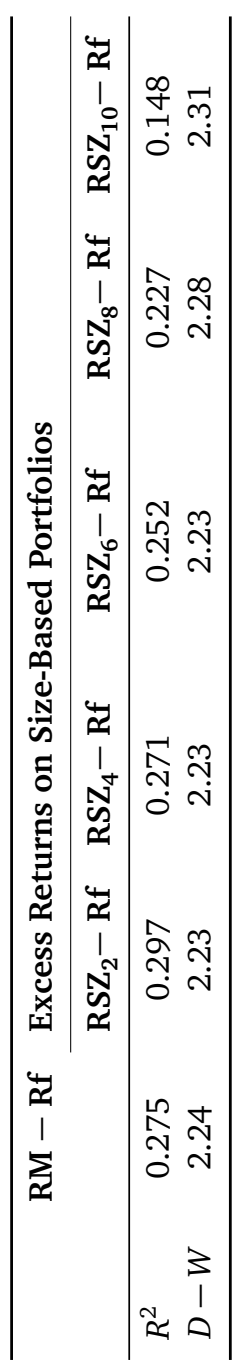

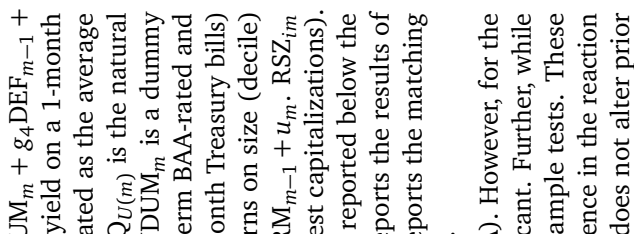

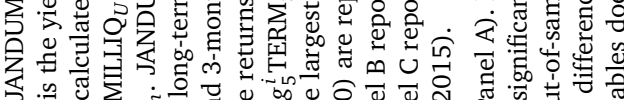

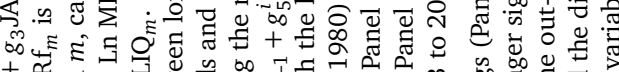

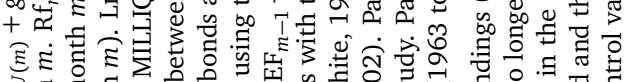

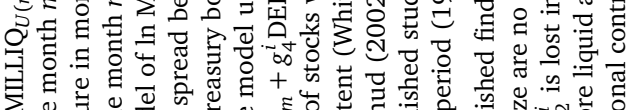
$\sum_{0}$ 焉 की

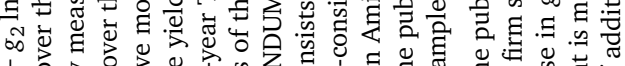

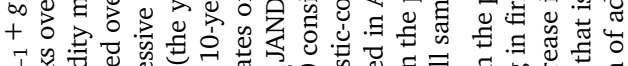

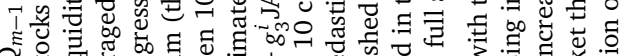

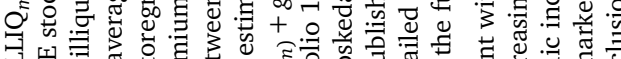

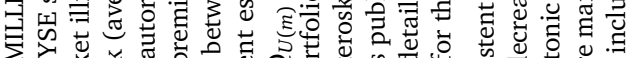

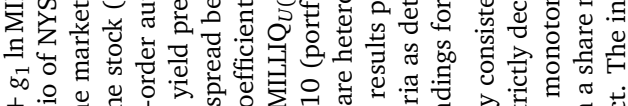

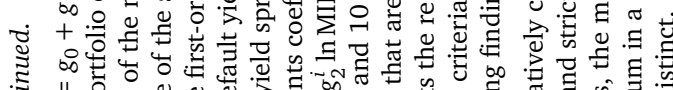

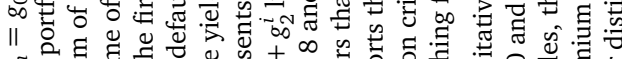
E

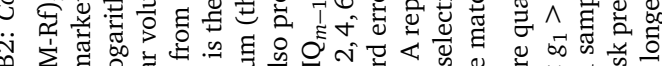

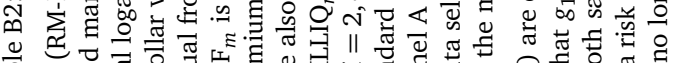

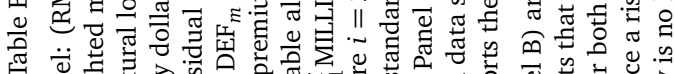

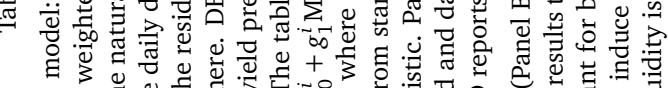

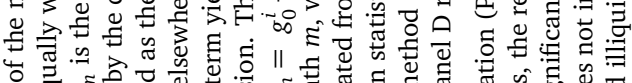

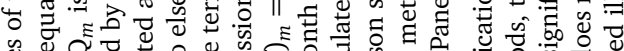

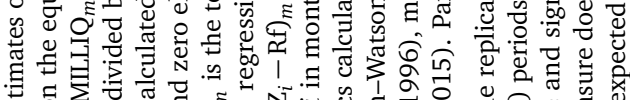
ष

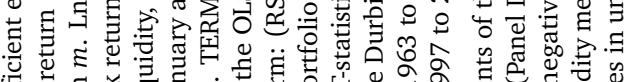

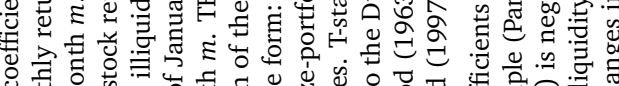

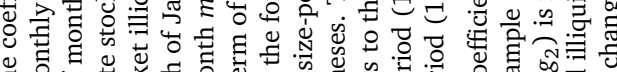

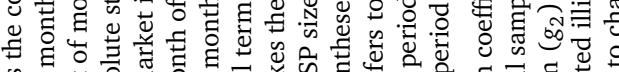

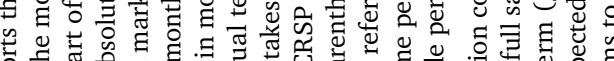

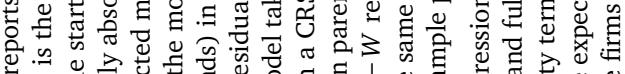

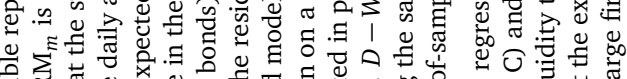

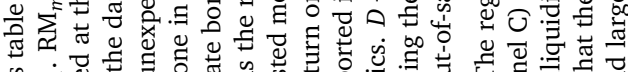

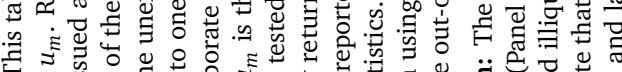

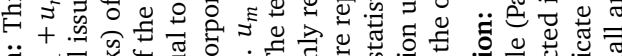

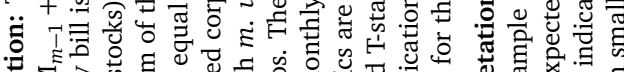

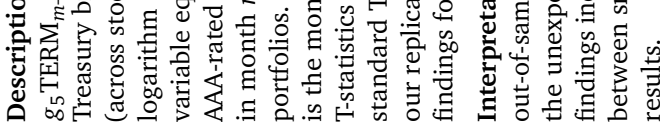




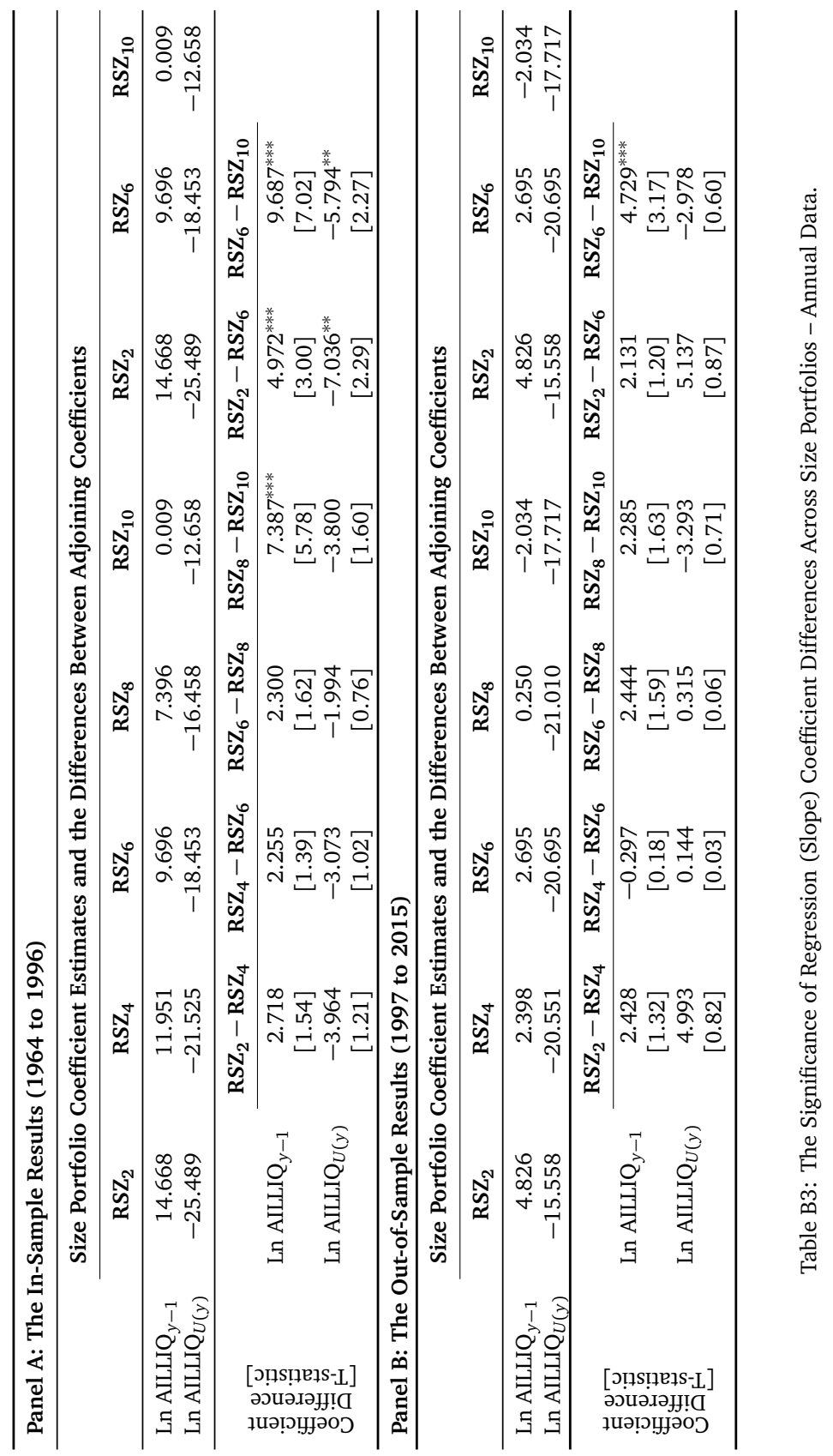




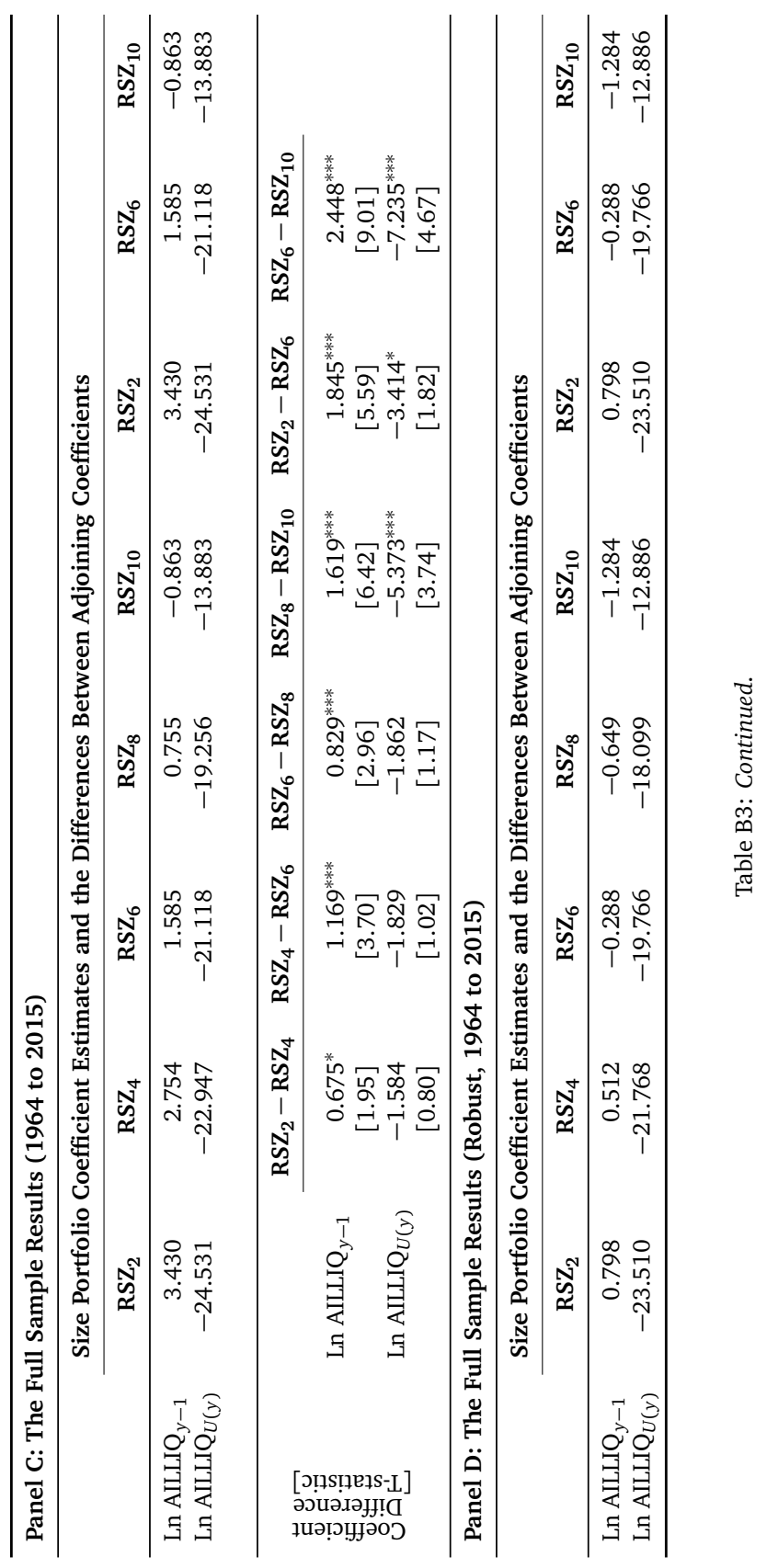




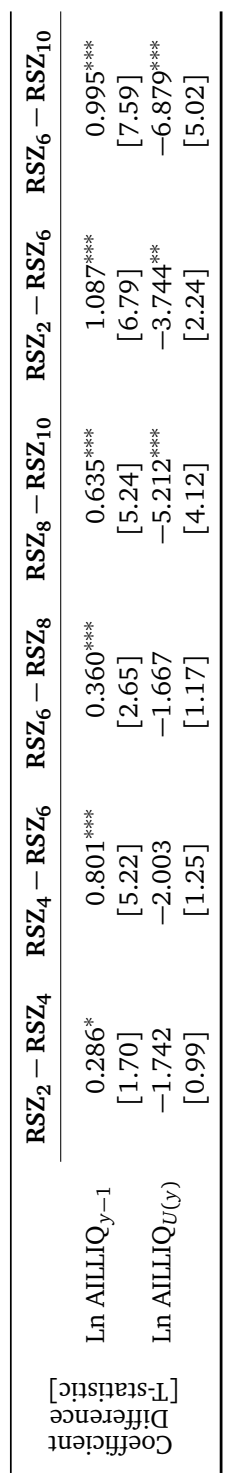

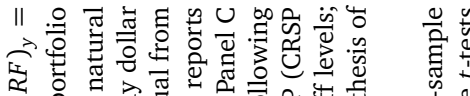

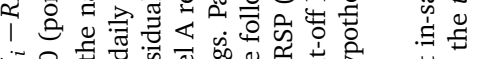

추을

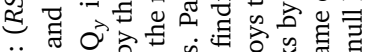

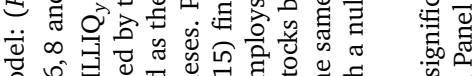

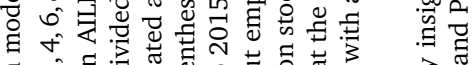

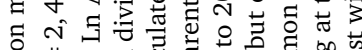

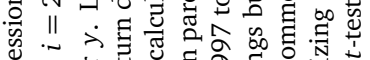

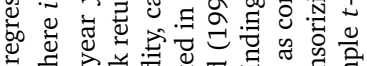

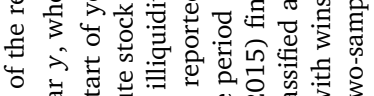

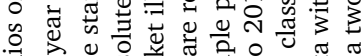

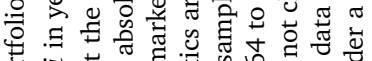

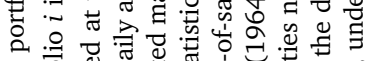

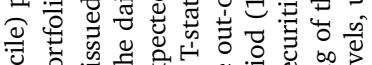

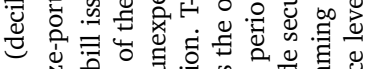

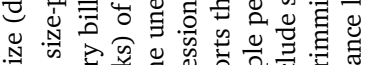

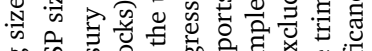

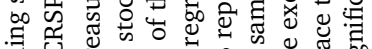

芯

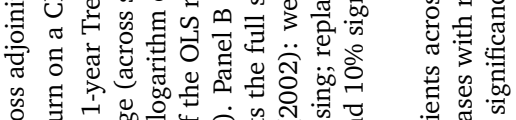

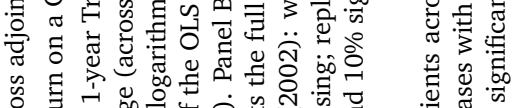

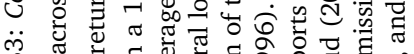

œ

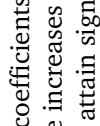

离范

릉요

\&

品

는

芯苞

品

悬焉

쿵ㅇ

幽,

क \&

. तु

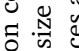

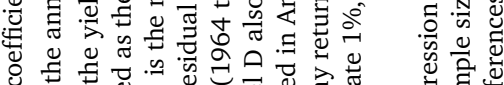

.

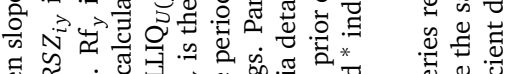

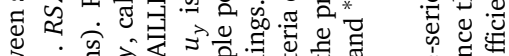

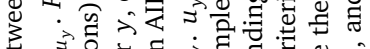

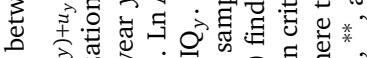

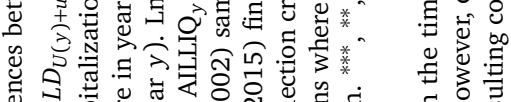

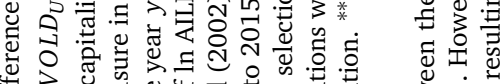

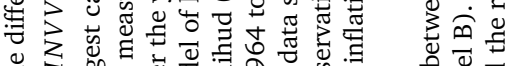

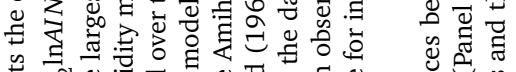

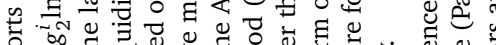

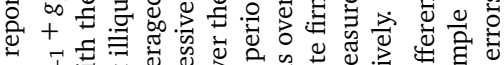

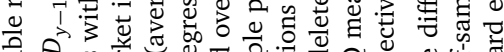

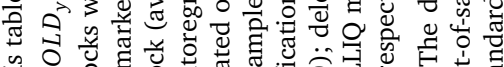

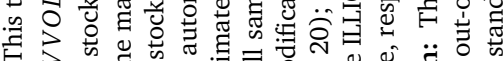

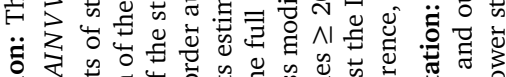

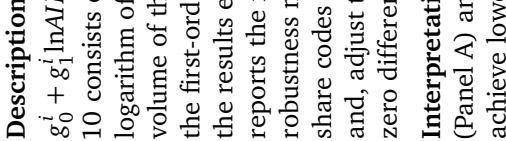




\section{References}

Acharya, V. and L. Pedersen. 2005. "Asset Pricing With Liquidity Risk." Journal of Financial Economics. 77: 375-410.

Amihud, Y. 2002. "Illiquidity and Stock Returns: Cross-Section and Time-Series Effects." Journal of Financial Markets. 5: 31-56.

Baker, M. and J. Wurgler. 2006. "Investor Sentiment and the Cross-Section of Stock Returns." Journal of Finance. 61: 1645-1680.

Barinov, A. 2014. "Turnover: Liquidity Or Uncertainty?” Management Science. 60: 2478-2495.

Ben-Rephael, A., O. Kadan, and A. Wohl. 2015. "The Diminishing Liquidity Premium." Journal of Financial and Quantitative Analysis. 50: 197-229.

Bessembinder, H. 2003. "Trade Execution Costs and Market Quality After Decimalization." Journal of Financial and Quantitative Analysis. 38: 747-777.

Brennan, M., T. Chordia, and A. Subrahmanyam. 1998. "Alternative Factor Specifications, Security Characteristics, and the Cross-Section of Expected Stock Returns." Journal of Financial Economics. 49: 345-373.

Brennan, M., S. Huh, and A. Subrahmanyam. 2013. "An Analysis of the Amihud Illiquidity Premium." Review of Asset Pricing Studies. 3: 133-176.

Chakravarty, S., V. Panchapagesan, and R. Wood. 2005. "Did Decimalization Hurt Institutional Investors?” Journal of Financial Markets. 8: 400-420.

Chakravarty, S., R. Wood, and R. Van Ness. 2004. "Decimals and Liquidity: A Study of the NYSE." Journal of Financial Research. 27: 75-94.

Chordia, T., R. Roll, and A. Subrahmanyam. 2001. "Market Liquidity and Trading Activity." Journal of Finance. 56: 501-530.

Chordia, T., R. Roll, and A. Subrahmanyam. 2011. "Recent Trends in Trading Activity and Market Quality." Journal of Financial Economics. 101: 243-263.

Durbin, J. 1970. "Testing for Serial Correlation in Least-Squares Regression When Some of the Regressors Are Lagged Dependent Variables." Econometrica. 38: 410-421.

Elandt, R. 1961. "The Folded Normal Distribution: Two Methods of Estimating Parameters from Moments." Technometrics. 3: 551-562.

French, K. 2008. "The Cost of Active Investing." Journal of Finance. 63: 1537-1573.

French, K., G. Schwert, and R. Stambaugh. 1987. "Expected Stock Returns and Volatility." Journal of Financial Economics. 19: 3-29.

Hasbrouck, J. 2009. "Trading Costs and Returns for U.S. Equities: Estimating Effective Costs from Daily Data." Journal of Finance. 64: 1445-1477.

Kendall, M. 1954. "Note on Bias in the Estimation of Autocorrelation." Biometrica. 41: 403-404.

Korajcyzk, R. and R. Sadka. 2008. "Pricing the Commonality Across Alternative Measures of Liquidity." Journal of Financial Economics. 87: 45-72.

Kyle, A. 1985. "Continuous Auctions and Insider Trading." Econometrica. 53: 1315-1335. 
Leone, F., L. Nelson, and R. Nottingham. 1961. "The Folded Normal Distribution." Technometrics. 3: 543-550.

Lou, X. and T. Shu. 2016. "Price Impact Or Trading Volume: Why Is the Amihud (2002) Illiquidity Measure Priced?” Working Paper. University of Georgia.

Mehra, R. 2008. Handbook of the Equity Risk Premium. Amsterdam. Elsevier.

Merton, R. 1980. "On Estimating the Expected Return on the Market: An Exploratory Investigation." Journal of Financial Economics. 8: 323-361.

Newey, W. and K. West. 1987. "A Simple, Positive Semi Definite, Heteroskedasticity and Autocorrelation Consistent Covariance Matrix." Econometrica. 55: 703-706.

Scholes, M. and J. Williams. 1977. "Estimating Betas from Non-Synchronous Data." Journal of Financial Economics. 5: 309-327.

Shumway, T. 1997. "The Delisting Bias in CRSP Data." Journal of Finance. 52: 327-340.

White, H. 1980. "A Heteroskedasticity-Consistent Covariance Matrix Estimator and a Direct Test for Heteroskedasticity." Econometrica. 48: 817-838. 